NBER WORKING PAPER SERIES

\title{
CHEAP TALK AND COORDINATION IN THE LAB AND IN THE FIELD: COLLECTIVE COMMERCIALIZATION IN SENEGAL
}

\author{
Fo Kodjo Dzinyefa Aflagah \\ Tanguy Bernard \\ Angelino Viceisza \\ Working Paper 26045 \\ http://www.nber.org/papers/w26045 \\ NATIONAL BUREAU OF ECONOMIC RESEARCH \\ 1050 Massachusetts Avenue \\ Cambridge, MA 02138 \\ July 2019
}

Funding for this study was provided by the CGIAR Consortium Research Program on Policies, Institutions, and Markets, the International Food Policy Research Institute (IFPRI), and the IFPRI Mobile Experimental Economics Laboratory. Viceisza is also grateful to the Economics Department at Duke University where some of this work was completed. Institutional Review Board (IRB) approval for this study was obtained from IFPRI and the Senegalese National Ethics Committee for Research in Health (CNERS). This RCT was registered in the American Economic Association Registry for randomized control trials under trial number 4400. We thank Elisabeth Sadoulet, Francisca Antman, Dan Ariely, Christopher Barrett, Patrick Bayer, Michael Carter, Jan Christopher, Claudio Ferraz, Erica Field, Fred Finan, Xavier Gine, Rachel Kranton, John List, Jeffrey Michler, Suresh Naidu, Joel Sobel, Mohammed Tesemma, Emilia Tjernstroem, Xiao Yu Wang, and Daniel Weiner for meaningful discussions. We also thank audiences at the Allied Social Science Association/National Economic Association meetings, Duke University (Center for Advanced Hindsight, Department of Economics, and Department of Political Science), the Economic Science Association North American meetings, the Experimental Methods in Policy Conference, the Food and Agricultural Organization, IFPRI, the NBER Transforming Rural Africa Conference, SEEDEC, University of Bordeaux (GREThA), University of Goettingen, University of Paris Dauphine, Vanderbilt University, the Workshop in Memory of John van Huyck, and the Workshop on Producers' Organizations in Agricultural Markets at Toulouse Economics for helpful comments. The views expressed herein are those of the authors and do not necessarily reflect the views of the National Bureau of Economic Research.

NBER working papers are circulated for discussion and comment purposes. They have not been peer-reviewed or been subject to the review by the NBER Board of Directors that accompanies official NBER publications.

(C) 2019 by Fo Kodjo Dzinyefa Aflagah, Tanguy Bernard, and Angelino Viceisza. All rights reserved. Short sections of text, not to exceed two paragraphs, may be quoted without explicit permission provided that full credit, including (C) notice, is given to the source. 
Cheap Talk and Coordination in the Lab and in the Field: Collective Commercialization in Senegal

Fo Kodjo Dzinyefa Aflagah, Tanguy Bernard, and Angelino Viceisza

NBER Working Paper No. 26045

July 2019

JEL No. C92,C93,D7,L26,O12,P32,Q13

\section{ABSTRACT}

Coordination is central to social interactions. Theory and conventional lab experiments suggest that cheap talk/communication can enhance coordination under certain conditions. Two aspects that remain underexplored are (1) the interaction between the number of players (group size) and communication and (2) how existing findings might play out in the field. We address both of these by studying a typical naturally-occurring setting that requires coordination; that is, one where members of agricultural cooperatives seek to jointly sell their output. Combining artefactual/lab-in-the-field experiments (LFEs), natural field experiments (RCTs), surveys, and cooperative records, we find that (1) revealing farmers' intended sales (i.e., cheap talk/ communication) yields enhanced collective commercialization (i.e., coordination), particularly in larger groups; (2) such cheap talk may lead to higher incomes for small-scale farmers; (3) participants transfer learning from the LFEs thus affecting subsequent behavior in the RCTs (i.e., the day-to-day environment). Our results contribute to existing literature by highlighting the potential for cheap-talk institutions to (1) boost coordination, particularly in settings with greater strategic uncertainty (e.g., larger farmer cooperatives), and (2) promote collective entrepreneurship and development.

Fo Kodjo Dzinyefa Aflagah

Department of Economics

University of Maryland

College Park, MD 20742

aflagah@econ.umd.edu

Tanguy Bernard

GREThA, University of Bordeaux

and International Food Policy

Research Institute (IFPRI)

Avenue Léon Duguit

33608 Pessac

France

t.bernard@cgiar.org
Angelino Viceisza

Department of Economics

Spelman College

350 Spelman Lane SW

Atlanta, GA 30314

and NBER

aviceisz@spelman.edu

Randomized controlled trials registry entry is available at https://www.socialscienceregistry.org/trials/4400 Author website (for future code, data release) is available at www.angelinoviceisza.com/papers An online appendix is available at http://www.nber.org/data-appendix/w26045 


\section{Introduction}

Many activities depend on coordination among a sometimes large number of agents; for example group projects, the meaning of language, and navigating traffic. From a game theory standpoint, coordination is required whenever there exist multiple, potentially Pareto ranked, equilibria and theory does not clearly predict behavior. In fact, without prior knowledge about others' intended actions, strategic uncertainty will likely steer agents away from activities that require coordination. This in turn leads to coordination failure; that is, agents choosing risk-dominant strategies over Pareto-dominant ones, thus leading to suboptimal outcomes (see for example Rosenstein-Rodan, 1943, who discusses how coordination failure can limit economic investment). Given their relevance to day-to-day situations, coordination games have featured prominently in the literature. ${ }^{1}$

Moreover, with coordination failure at the heart of certain development traps (Wydick, 2007), a key policy question has been how to enhance coordination (Hoff, 2001). For example, Devetag and Ortmann (2007) point at several factors that may improve coordination: (1) smaller group sizes (e.g., Van Huyck et al., 1990); (2) lower attractiveness of the secure relative to the risky action (e.g., Brandts and Cooper, 2006); and (3) certain types of cheap talk/communication in certain types of games (e.g., Farrell, 1987; Cooper et al., 1992; Farrell and Rabin, 1996). Yet, as Avoyan and Ramos (2017) argue, while communication has been lauded for its potential to enhance coordination, there are also instances where it has had no effect (e.g., Cooper et al., 1992).

One aspect that has received limited attention is the interaction between the number of players (i.e., group size) and communication (one exception is Feltovich and Grossman, 2015). In addition, most prior literature on coordination and its drivers (in particular communication) is theoretical and/or based on conventional laboratory experiments. ${ }^{2}$ Cooper and Weber (2019) also conclude that coordination games like ours (i.e., threshold games) and those that relate to problems in organizations (of which farmer cooperatives are an example) require further study. So, if we want to better understand drivers of coordination in day-to-day settings, it is useful to complement existing findings with field evidence.

In this paper, we explore the impact of cheap talk on coordination and whether this effect varies with group size, in a field context where strategic uncertainty has historically led to

\footnotetext{
${ }^{1}$ Section 3 will discuss our work in the context of prior literature. Some overviews of the experimental literature on coordination are Ochs (1995), Goeree and Holt (2002), Camerer (2003), Devetag and Ortmann (2007), Rapoport and Seale (2008), Van Huyck and Battalio (2008), and Cooper and Weber (2019).

${ }^{2}$ Elfenbein et al. (2018) study cheap talk in a field context - charity on eBay - that is fundamentally different from ours. They find that most buyers avoid cheap talk listings when there are credible quality signals, thus limiting the effect of cheap talk.
} 
coordination failure. ${ }^{3}$ We study farmer cooperatives that seek to sell members' agricultural production collectively - a setting that represents much of the developing and developed world. Farmer groups have received quite some attention in policy and research. For example, the United Nations designated 2012 as the international year of cooperatives, since 85\% of farms worldwide are small family farms and most of them participate in cooperatives. Barrett (2008) argues that mechanisms aimed at facilitating smallholder organization (e.g., cooperatives) are central to stimulating market participation. At the same time, cooperatives are not always able to achieve the goal of selling collectively (see for example Fafchamps and Hill, 2005; Aldana et al., 2007; Hellin et al., 2007; Ragasa and Golan, 2014). Our primary goal is not to promote collective commercialization, as we are agnostic regarding its effective capacity to increase farmers' income. ${ }^{4}$ Instead, we seek to understand why, in groups designed for the purpose of collective commercialization, farmers are unwilling to do so. In particular, because those same farmers report believing that collective commercialization would lead to higher incomes if the group were able to aggregate a large enough quantity.

We hypothesize that the uncertainty surrounding others' likelihood to sell through the cooperative (i.e., strategic uncertainty) is key to explaining the lack of collective commercialization (i.e., coordination) in these groups. ${ }^{5}$ So, there may be a role for communication (i.e., cheap talk) prior to commercialization. Our intervention thus seeks to address a coordination dilemma by revealing salient information on the planned actions of all group members prior to commercialization. This form of communication is quite different from the casual, mostly one-on-one "chit chat" that group members typically engage in. Based on data from the context in question (Bernard et al., 2014) as well as prior literature (e.g., Devetag and Ortmann, 2007), we hypothesize that (1) beliefs about others' sales to the group are key to one's decision to sell through the group; (2) larger groups have more difficulty coordinating; and (3) communicating others' intentions to sell through the group (i.e., cheap talk) can

\footnotetext{
${ }^{3}$ Throughout, we use the following terms interchangeably: (1) cooperatives, farmer groups, and producer organizations; (2) farmers, smallholders, members, players, and subjects; (3) cheap talk, communication, intentions, plans/planned actions; and (4) coordination and collective commercialization/selling.

${ }^{4}$ Collective commercialization is often promoted in Sub-Saharan Africa on the grounds of imperfect competition between traders in remote and thin markets, which in turn leads to rent extraction from farmers. By aggregating farmers' production, collective commercialization offers the possibility to (1) reach distant but larger markets (e.g., due to lower transaction costs, Key et al., 2000) or (2) negotiate better with local traders. As reviewed by Dillon and Dambro (2017), the empirical evidence is mixed. For example, Bergquist (2017) finds a low pass-through of price premiums from traders to farmers in Kenya, while Casaburi and Reed (2017) find a high pass-through in Sierra Leone. Bernard et al. (2008) find positive but limited impacts of cooperatives in Ethiopia and Ashraf et al. (2009) find positive, but unsustained, impacts in Kenya.

${ }^{5}$ Bernard et al. (2014) find that among a sample of 27 groundnut-producing cooperatives in Senegal, $67 \%$ of group members believe that, if presented with the opportunity, other members would by-pass sales through the group and sell individually to a trader for a potentially lower, but more certain payoff. There may of course be other reasons why cooperatives are (un)able to sell collectively; e.g., Casaburi and Macchiavello $(2015,2019)$ and Hill et al. (2014) discuss commitment sanctions and deferred payments respectively.
} 
increase the likelihood of collective commercialization, particularly in larger groups.

In order to test these hypotheses, we work with a sample of 79 Senegalese groundnutproducing cooperatives and close to 900 individual group members. First, in a subsample of these cooperatives, randomly selected group members participate in neutrally framed, highstakes coordination games (i.e., artefactual field experiments in the terminology of Harrison and List, 2004, hereafter, lab-in-the-field experiments/LFEs) where we exogenously vary (1) the experimental group size, (2) the threshold required for coordination, and (3) the presence of players' intentions to coordinate (i.e., cheap talk). Second, six months later, we implement a comparable naturally-occurring intervention (i.e., a natural field experiment in the terminology of Harrison and List, 2004, hereafter, randomized controlled trial/RCT) with the full sample of cooperatives. Shortly after the harvest period, we collect all group members' plans to sell through the cooperative in the upcoming commercialization season. In a random subset of these cooperatives, members' intentions are revealed in a public meeting right before commercialization starts. Since these are existing cooperatives, unlike in the LFEs, it is infeasible to exogenously manipulate the group size and coordination threshold. ${ }^{6}$ Thus, both the LFEs and the RCT are key for testing our hypotheses. The LFEs provide a "direct" test, allowing us to assess whether group size proxies for strategic uncertainty or the likelihood of achieving the threshold. Meanwhile, the RCT forms a "real-life" test, without the possibility to exogenously vary all parameters of interest. Finally, we supplement this spectrum of experiments with survey data and cooperative records (i.e., administrative data).

Our findings are as follows. First, revealing aggregate intentions (i.e., cheap talk) improves coordination in both the LFEs and the RCT, particularly in larger groups. These results are relatively robust to (1) farmers' preferences (in particular, over risk and time), (2) a series of placebo tests confirming that intentions are balanced at baseline, (3) potential social desirability bias, which we rule out by comparing survey responses to group-administrative data, and (4) correcting for multiple hypothesis testing according to the Holm-Bonferroni approach. In short, this set of findings suggests that cheap talk primarily reduces the strategic uncertainty around members' likelihood of selling through the cooperative.

Second, there is suggestive (i.e., weak) evidence that the intervention positively impacts revenues (welfare) among farmers who produce smaller quantities. Since collective commercialization is both more relevant (due to fixed transaction costs) and more difficult (because

\footnotetext{
${ }^{6}$ In the day-to-day context, the membership of farmer groups is likely to be driven by location characteristics (e.g., population density) and group performance. Accordingly, group size is difficult to manipulate. Moreover, the threshold may be farmer-specific (in that farmers can be heterogenous with respect to their commercialization capacities) or group-specific (depending on location as well as leaders' commercialization capabilities). So, the coordination threshold is not readily observable and also difficult to vary.
} 
a larger pool of farmers is needed to achieve coordination) for small-scale farmers, this set of results suggests that cheap talk may be beneficial where it is most needed. That is, in larger groups that are comprised of a greater number of small farmers and thus, where there is greater uncertainty over others' actions.

Finally, behavior in the "lab" (LFEs) transfers to behavior in the "field" (RCT). We exploit the random selection of individuals and find that, in the same cooperative, LFE participants were more likely to engage in day-to-day collective commercialization than nonLFE participants. In other words, consistent with the literature on transfer (e.g., Cooper and Van Huyck, 2016) but perhaps contrary to Voors et al. (2012), participants learn from the LFEs. Similar findings have been documented by Cardenas and Carpenter (2005) and Turiansky (2017). ${ }^{7}$ Our study thus also contributes to the literature linking results across the spectrum of experiments; see for example, Levitt and List (2007), Camerer (2015), Viceisza (2016) and the references within. ${ }^{8}$ Like others, our findings support the use of LFEs in combination with RCTs (and other approaches) to better understand the mechanisms that are at play. At the same time, researchers should take heed that participation in LFEs may affect subjects' future behavior (comparable to Zwane et al., 2011, in a survey context).

The remainder of the paper proceeds as follows. Section 2 places our study within the context of the Senegalese groundnut sector and provides further evidence of strategic uncertainty and coordination failure in related cooperatives. Section 3 discusses our framework and hypotheses in the context of existing literature. Section 4 details our study design and empirical strategy. Section 5 covers our main findings. Finally, Section 6 concludes.

\section{Strategic uncertainty in Senegalese cooperatives}

Groundnut production has long been the backbone of the Senegalese economy. At independence, the sector employed $87 \%$ of the agriculturally active population in rural areas and occupied 50\% of the cultivated land. According to Caswell (1984), groundnut processing contributed to $42 \%$ of all industrial output and groundnuts represented $80 \%$ of all export revenues. Over time, however, revenues from the sector have steadily declined due to (1) external factors such as lower international prices, the end of preferential tariffs, droughts, oil shocks, and exchange rates and (2) internal factors such as mismanagement and politics

\footnotetext{
${ }^{7}$ This is not too different from the discussions by Charles Holt and co-authors in a series of papers on (the benefits of) classroom experiments in Journal of Economic Perspectives in the late 1990s.

${ }^{8}$ Some examples include Barr et al. (2010) who correlate results from dictator games with absenteeism of school teachers in Uganda; Finan and Schechter (2012) who relate behavior in trust games to individuals' responses to vote buying in Paraguay; Stoop et al. (2012) who study cooperation among fishermen in the Netherlands; and Hoel et al. (2017) who use public goods games to relate spousal cooperation to householdlevel productive inefficiencies in Senegal.
} 
at various levels of the sector. In the late 1990s, these shocks gradually led to privatization of all segments of the value chain, after several attempts at restructuring.

Prior to the above reforms, a dense network of state-controlled cooperatives was the exclusive interface between farmers and other actors. Through these groups, farmers accessed credit, inputs, and extension services. Each year, the price of groundnut was fixed at the national level and all marketed production was collected through cooperatives. Following privatization, the role, functioning, and capacity of producer cooperatives changed significantly, in particular with regard to collective commercialization. Although privatized in 2001, Suneor, the principal end-buyer of groundnuts still existed, but procured production via private traders who were ensured a fixed price upon delivery at the processing plant. Traders could purchase from cooperatives or from farmers individually. Competitive forces were expected to support producer prices, but issues of local monopsony and potential collusion led to general dissatisfaction with this system. In 2010, the export-monopoly previously granted to Suneor was abolished, facilitating the entry of new players who could also procure groundnuts from cooperatives or individual farmers.

In short, these reforms led to important changes in farmers' ability to coordinate within cooperatives. Previously, there were no strategic complementarities between members of a group: the price per kilogram $(\mathrm{kg})$ of groundnut was the same whether the cooperative aggregated small or large quantities. At the same time, there was no need to worry about others' decisions to sell through the cooperative. In the new system, group members became strategic complements since the cooperative could obtain better per-unit prices by aggregating production and accessing larger, more distant markets/processing plants, or by negotiating more strongly with local traders. However, farmers could also sell directly to local traders. So, this presents a tradeoff: While aggregation through the cooperative could lead to a higher unit price, receipt of such funds would usually be delayed relative to local traders who pay cash on delivery. Moreover, the price premium obtained from collective commercialization would also depend on the quantity that other members sell through the cooperative, which is uncertain when a given farmer is visited by the trader.

While groundnut cooperatives remain active in input and credit provision, their capacity to aggregate and sell output has weakened considerably. Bernard et al. (2014) document commercialization among close to 300 members of 27 groundnut cooperatives whose main, stated objective is collective commercialization. The data indicate that a great majority of members sells individually to local traders in spot market transactions. ${ }^{9}$ In fact, only 11 of the 27 groups had sold collectively in 2011, and for those that did, only half of the

\footnotetext{
${ }^{9}$ Less than $7 \%$ of farmers deal regularly with the same trader and pre-harvest contracting occurs in less than $2 \%$ of cases.
} 
members participated. This limited involvement contrasts with farmers' perceived potential for collective commercialization: While $79 \%$ of farmers cited problems when attempting to sell individually (e.g., lack of transportation to reach more lucrative markets, insufficient knowledge of current prices, and limited production to negotiate better prices), practically all respondents were convinced that group commercialization could alleviate such constraints. These perceptions are also consistent with prior literature on transaction costs in market participation (see for example, Key et al., 2000).

Bernard et al. (2014) also collect members' aversion to the strategic uncertainty arising from collective commercialization using a framed version of the instrument by Heinemann et al. (2009). Subjects were presented with the choice to sell to a trader at a certain price or sell through the group at a higher but uncertain price that depends on the number of other members selling through the group. The price offered by the trader was incrementally raised until subjects switched from selling through the cooperative to selling to the trader. The results suggest that aversion to strategic uncertainty is negatively correlated with individuals' effective sales through the cooperative. This correlation clearly dominates that of other preferences such as risk, time, and social (altruism). When asked about other group members' likely response to the above strategic uncertainty question, $67 \%$ of the sample believed that those members would by-pass sales through the group and sell individually to a trader for a potentially lower payoff than they would.

Overall, reforms in the groundnut sector paved the way for issues of strategic uncertainty in Senegalese cooperatives. It is for these reasons that we assess the impact of a cheaptalk/communication intervention.

\section{Framework, literature, and hypotheses}

\subsection{Framework}

In line with the above context, our framework is a critical-mass/threshold coordination game. There are $N \in \mathbb{N}$ players, each of whom $j$ has a positive endowment $V_{j} \in \mathbb{N}$. All players simultaneously choose an amount $A_{j} \in\left[0,1, \ldots, V_{j}\right]$ to send to the group (the equivalent of commercializing collectively) and keep the remainder $V_{j}-A_{j}$ (the equivalent of selling individually/via traders). Any quantity $A_{j}$ sent to the group, earns a high return $H$ if all players jointly send a quantity $A=\Sigma_{j} A_{j} \geq T$ to the group, where $T$ represents some threshold. Otherwise, if they send a quantity $A<T, A_{j}$ earns a low return $L<H$. Whatever a player chooses to keep individually, that is $V_{j}-A_{j}$, earns a medium return $M$, where $L<M<H$. 
As discussed in Sections 1 and 2, there are several reasons why $L<M<H$ may hold. In particular, changes in government policies and market conditions in Senegal led to farmer cooperatives losing bargaining power relative to traders. Yet, if able to aggregate sufficient production and negotiate better contracts, cooperatives would offer better prices $(H)$ than traders would at the farm gate $(M)$. On the other hand, if unable to aggregate/secure such contracts, farmers would have to resort back to selling individually, i.e., in absence of the cooperative. Due to waiting times and high fixed transaction costs, this would lead to lower effective prices $(L)$. So, these payoffs reflect the trade-off that exists between commercializing collectively through the cooperative and selling individually (primarily via traders). Moreover, they are consistent with farmers' beliefs about the benefits to collective commercialization, as discussed in Section 2.

Accordingly, player $i$ 's expected payoff can be expressed as: ${ }^{10}$

$$
\Pi\left(A_{i}\right)=p A_{i} H+(1-p) A_{i} L+\left(V_{i}-A_{i}\right) M
$$

where $p=P(A \geq T)$. It is clear that equilibria in this game will be driven by player $i$ 's belief, $p_{i}$, about the likelihood of the threshold being surpassed, $p$. In other words, contributions to the group - i.e., how much the farmer chooses to commercialize collectively - will depend on the player's sense of strategic uncertainty in the game. If s/he expects $A$ to surpass $T$, $p_{i}=1$, the player should send all of the endowment to the group, i.e., $A_{i}=V_{i}{ }^{11}$ If $\mathrm{s} /$ he expects $A$ not to surpass $T, p_{i}=0$, the player should keep the full endowment, i.e., $A_{i}=0$. If $\mathrm{s} /$ he expects a scenario in between these two extremes, the player should diversify by selling $A_{i} \in\left\{1, \ldots, V_{i}-1\right\}$ through the cooperative and the remainder individually.

As discussed in Section 2, farmer cooperatives seem to have been unable to commercialize collectively in this setting in recent years. Moreover, most members believe that other members are more likely to sell individually to traders than collectively through the cooperative. In short, empirical evidence suggests that $p=0$ or close to it. So, a key question is whether and if so, how this likelihood can be increased, given farmers believe it would be beneficial to do so. In order to develop related hypotheses, which will form the basis of the study design discussed in Section 4, we now turn to prior literature on the determinants of coordination.

\footnotetext{
${ }^{10}$ Here, we abstract from risk and social preferences by assuming that $H, M, L$ capture players' true payoffs. In other words, we do not work with the more general "utility" function. In the empirical analysis, we check for internal validity with regard to a range of characteristics including social, risk, and time preferences.

${ }^{11}$ If $p=1, \Pi\left(A_{i}=V_{i}\right)>\Pi\left(A_{i}<V_{i}\right)$ since $H>M$. To see this, note that $\Pi\left(A_{i}=V_{i}\right)=V_{i} H=$ $A_{i} H+\left(V_{i}-A_{i}\right) H$ and $\Pi\left(A_{i}<V_{i}\right)=A_{i} H+\left(V_{i}-A_{i}\right) M$. So, if the threshold is surpassed, any amount sold individually (to traders) leads to lower returns than if it had been sold collectively (via the cooperative).
} 


\subsection{Related literature and hypotheses}

There is a relatively extensive theory and lab literature on coordination (in games) and the potential determinants thereof (see for example Farrell, 1987; Ochs, 1995; Farrell and Rabin, 1996; Crawford, 1998; Goeree and Holt, 2002; Camerer, 2003; Rapoport and Seale, 2008; Van Huyck and Battalio, 2008, for some overviews). The parts of the literature that relate most closely to our setting are on (1) coordination games with Pareto-ranked equilibria, which cover both order-statistic games (e.g., Van Huyck et al., 1990; Van Huyck and Battalio, 2008) and stag-hunt games (e.g. Cooper et al., 1992; Battalio et al., 2001; Charness and Grosskopf, 2004) and (2) preplay communication/cheap talk (see for example Blume and Ortmann, 2007; Avoyan and Ramos, 2017, and some of the previous references). ${ }^{12}$

Devetag and Ortmann (2007) and Cooper and Weber (2019) survey some of this literature and both point at a range of common factors that may enhance coordination. Among those are (1) smaller group sizes; (2) certain types of cheap talk/communication in certain types of games; and (3) lower attractiveness of the secure action relative to the risky one. As Feltovich and Grossman (2015) note, there has been little work jointly investigating the effect of group size and cheap talk. In fact, their study is one of the few exceptions. ${ }^{13}$ It is also closest to ours, but there are a few key differences. First, their setting is a threshold public-good game with a dichotomous choice ("contribute" or "not"). Second, their communication takes the form of one subject/player sending a message that "Everyone should choose [action]". This is different from how we implement cheap talk, as will be discussed further below. Third, their group sizes are smaller. Finally, we examine this interaction both in the "lab" and "field". Particularly in the latter case, there may be pre-existing experiences that impact the interaction between group size and cheap talk.

In order to state the main hypotheses that form the basis of the experimental design in Section 4, we further extend the framework discussed in Section 3.1. Suppose there is a pre-stage to the game in which all players simultaneously reveal an intended action towards the group $A_{j}^{\prime}$ (i.e., $N$-way communication) prior to taking the "true" action $A_{j}$. Player $i$ will use intentions $A_{j}^{\prime}$ to inform her/his belief $p_{i}$ about $p$ only if s/he believes those intentions. While some of the literature on communication has suggested that players may seek to deceive others, particularly when sending non-costly and non-binding messages, there is no such incentive in this game. In other words, unlike Prisoner's dilemma/public-good type

\footnotetext{
${ }^{12}$ There is also a tangentially related literature on the link between strategic uncertainty and cultural diversity (see for example, Kets and Sandroni, 2017)

${ }^{13}$ Balliet (2010) conducts a meta-analysis of 45 social-dilemma experiments and finds a positive interaction between group size and the effect of communication. However, this interaction is not robust to controlling for other relevant variables and removal of two outliers (see Feltovich and Grossman, 2015, for a more detailed discussion/analysis).
} 
games, a player cannot "free-ride" by sending a high intention $A_{j}^{\prime}$ and then taking a low action $A_{j}$. If a player truly believes that a high signal will cause others to increase their contributions to the group, this player should align her/his actual contribution with such intentions. This is the same argument that has been made by for example Farrell and Rabin (1996) and Crawford (1998); for example, recall the "reassurance" role of cheap talk in stag-hunt games.

So, assuming that players believe intentions $A_{j}^{\prime}$, these can be quite informative. In particular, player $i$ will substitute $A_{-i}^{\prime}$ for $A_{-i}$ in order to more precisely assess the likelihood of surpassing the threshold $T$. With this extended framework and the above referenced findings from prior literature in mind, we state the following hypotheses.

Hypothesis 1. As the group size $N$ increases, player $i$ decreases her/his contribution to the group $A_{i}$, since coordination failure is more likely. In other words, due to strategic uncertainty, smaller groups are more conducive to coordination.

Hypothesis 2. Player $i$ will set $p_{i}=p=1$ and thus $A_{i}=V_{i}$ if revealed intentions are such that $\Sigma_{j} A_{j}^{\prime}=A^{\prime} \geq T$. In other words, cheap talk can reduce coordination failure if aggregate intentions surpass the threshold.

Hypothesis 3. The effect of cheap talk (i.e., $\Sigma_{j} A_{j}^{\prime}$ relative to $T$ ) will increase with the group size $N$. In other words, due to strategic uncertainty, cheap talk is more effective in larger groups. However, the direction of the effect will depend on whether or not aggregate intentions surpass the threshold. This hypothesis basically combines hypotheses 1 and 2 .

\section{$4 \quad$ Study design}

With the above context in mind, our study is mainly designed to test whether (1) knowing others' aggregate intentions about collective commercialization impacts effective sales to the group and (2) this effect is more salient in larger versus smaller groups. As mentioned in Section 1, we are unable to exogenously manipulate two key parameters - the group size $N$ and the threshold $T$ - in the naturally-occurring environment. As such, group-size effects in the day-to-day setting could be capturing other (potentially unobserved) characteristics. For example, larger groups may (1) offer better services to farmers to begin with (e.g., input, credit, or negotiated prices); (2) be more likely to achieve a given threshold level, ceteris paribus; and (3) be associated with greater strategic uncertainty due to a greater number of "moving parts" (i.e., number of players). Accordingly, our design is based on a two-stage 
empirical strategy. First, we fully test our predictions through controlled, neutrally framed LFEs in which we are able to observe and manipulate the group size $(N)$ and coordination threshold $(T)$ as well as other aspects such as external uncertainty and the premium for coordination $(H)$. Then, we test our results in a naturally-occurring RCT where we do not manipulate the above parameters. The LFEs and RCT were conducted six months apart in order to clearly separate outcomes. The timing of these experiments and related data collection was as follows:

1. LFEs: From May to June 2013, randomly selected farmers from 28 cooperatives participated in variants of neutrally-framed, high-stakes, threshold coordination games (as explained in Section 4.1). A presurvey collecting basic (behavioral) characteristics was also administered at this time.

2. RCT: From November 2013 to February 2014, 79 farmer groups (including 26 of the 28 that were in the LFEs) participated in variants of intention-revelation treatments (as explained in Section 4.2). In particular, intentions were revealed 2-4 weeks prior to the start of the actual commercialization period.

3. Post-survey and administrative data: In June 2014, a follow-up survey was administered to 10-12 randomly selected members of the cooperative (median size is 24 , ranging from 4-91) in order to gauge members' sales. Administrative data on individual members' commercialization were also collected from the books/records of the farmer groups for the 2014 season.

Because some groups that were selected for the RCT did not participate in the LFEs, we are able to control for LFE participation in all RCT-related estimations. Furthermore, because individuals were randomly selected for the LFEs, we are able to assess whether participation in this set of experiments affected subsequent behavior in the RCT. Table 1 summarizes the relationship between the LFE and RCT samples.

\subsection{LFEs}

The LFEs were based on two main treatments (see online appendix for detailed instructions): (1) a baseline coordination game (BCG) and (2) the same coordination game but with intentions revealed (i.e., communication/cheap talk) prior to play (CCG). These treatments were randomly assigned across experimental groups of subjects, which were created by randomly drawing members from existing cooperatives to form sets of players of size $N$ equal to 10 or 20. All players in a given experimental group were members of the same cooperative. Table 2 gives the sample distribution across the BCG and CCG. 
In the BCG, each player $j$ had an endowment $V_{j}$ of six chips. Each chip was worth 2000 West African francs/CFA (the equivalent of approximately 5 US dollars) if held individually. This was $M$. So, players were explained at the beginning of the game that they held an endowment of $12000 \mathrm{CFA}$. To mitigate windfall/house money effects, this endowment was framed as payment for the presurvey. The payoff for each chip sent to the experimental group was dependent on whether or not the threshold $(T)$ was reached/surpassed. If $A \geq T$, each chip was worth $3000 \mathrm{CFA}$ (the equivalent of $H$ ); if not, each chip was worth $500 \mathrm{CFA}$ (the equivalent of $L$ ). So, each player had to decide how many of the six chips to send to the group $\left(A_{j}\right)$ and how many to keep individually $\left(6-A_{j}\right)$, as shown in the panel to the left of the "big plus" sign in Figure A1.

The CCG was identical to the BCG with one exception: prior to choosing and committing to $A_{j}$, each player was asked to reveal their intended action $A_{j}^{\prime}$ to the experimenter; that is, how much the player planned to send to the experimental group. This intention, which was confidentially revealed to all other players $-j$, in random order, on a board in front of the room, indicated a given player's likely action. However, it was not a binding commitment and as such, other players did not know with full certainty that $A_{j}$ would be the same as $A_{j}^{\prime}$. It is in this sense that it was cheap talk and a form of (structured) communication.

Apart from the BCG and the CCG, we randomly varied $N, T, H$, and the presence of external uncertainty as separate treatments. First, we varied $H$ and the presence of external uncertainty because prior literature has shown that attractiveness of the secure versus the risky action may impact coordination (recall Section 3.2). Second, we varied $T$ because in a day-to-day context (in particular, the RCT) group size $N$ is likely to be correlated with other characteristics such as the perceived likelihood of achieving the threshold. However, as previously discussed, we are unable to exogenously vary this parameter in the RCT. Experimental variation in $T$ enables us to better understand what mechanism is at play.

To see this, consider the following: If the level of $T$ is fixed, it should be easier to coordinate in large groups than in small groups, since the former are more likely to reach the threshold. So, communication should be less informative in large (relative to small) groups for a fixed level of $T$. On the other hand, if communication is more informative in large groups, despite the level of $T$ being fixed, this must be because of greater strategic uncertainty surrounding other players' actions. Similarly, if the average (i.e., per-player) number of chips needed to surpass the threshold is fixed across small and large groups, but communication matters differentially across $N$, this also suggests that strategic uncertainty is the main mechanism at play. Since we are unable to (1) experimentally control $T$ in the RCT and (2) fully isolate these mechanisms in the day-to-day environment, we thus rely on the LFEs as a crucial part of our design in order to argue mechanisms. 
Two primary aids were used when explaining the game. First, monetary payoffs were explained by displaying actual CFA bills on a board at the front of the room, also making "real stakes" more salient. Second, many hypothetical examples were used. For example, the experimenter and his assistant as well as pairs of subjects role-played through different scenarios. We also tested subject understanding by asking specific players to calculate such payoffs. A substantial part of the LFE sessions was dedicated to the instruction phase.

In the CCG, the exact same procedure as in the BCG was followed, except that prior to subjects making their actual decisions $\left(A_{j}\right)$, the experimenter went around the room and asked players in private to reveal their intended actions $\left(A_{j}^{\prime}\right)$. Subjects were explained that this information would be collected by the experimenter and confidentially displayed in random order on a separate board at the front of the room. It was made clear that this was an intended, but non-binding action. Figure A1 also shows the logic behind the CCG. It was identical to the BCG, except for an additional board (right panel of Figure A1), which contained randomly ordered intentions $A_{j}^{\prime}$ and the aggregate $A^{\prime}$.

The BCG and the CCG were implemented between subjects (sessions), since introducing intentions mid-session would have complicated the protocol. The (experimental) group size, $N$, was fixed at either 10 or 20 during a session. So, $N$ was varied across sessions/between subjects. The threshold, $T$, was 40 or 50 in 10-person groups and 40, 50, 80, or 100 in 20person groups. $T$ was varied randomly across rounds. $H$ was either 3000 or 2500 CFA per chip and was varied randomly across rounds. Whether or not there was external uncertainty was implemented as follows. Subjects were informed that there was a 50 percent chance that due to bad luck $H$ would be 1500 CFA per chip (instead of 2500 or 3000). This was varied across rounds by flipping a coin.

The experiments were conducted in vacant classrooms of village schools. Each experiment session comprised the following components: (1) a presurvey collecting basic information (available from the authors upon request); (2) an introduction covering issues such as the purpose of the session (that is, to present participants with different decision-making scenarios) and the fact that participants would be paid for the decisions made during the session; (3) four rounds of decisions with no feedback, followed by debriefing; (4) a postsurvey collecting other information (available from the authors upon request); and (5) payment in private based on one randomly selected round. The sessions lasted 2.5-3 hours and average earnings were 9,500 CFA (approximately 20 US dollars), relative to a daily wage equivalent in this region of 5,000 CFA. So, these LFEs were relatively "high stakes". 


\section{$4.2 \mathrm{RCT}$}

We worked with 79 groundnut-producing cooperatives - including 26 of the 28 with which we implemented the LFEs - comprising close to 900 individuals. These cooperatives are part of two umbrella federations (i.e., conglomerates of cooperatives) in the Bassin Arachidier, which is the main groundnut production zone of Senegal. From November to December 2013, two leaders of each farmer group attended a two-day training conducted by two development specialists. The training focused on the potential, pitfalls, and conduct of collective commercialization; in particular, strategies for identifying distant buyers, negotiating prices, and organizing transportation. Participants were instructed to conduct a briefing meeting with all cooperative members upon returning to their village, to report the gist of what was covered during the training. Trainees were also provided with standardized booklets to keep records of each member's contribution to the group's sales in the upcoming commercialization season. A reward of 10,000 CFA was promised for filling in the booklets with all the requested information. All groups eventually received such reward.

After the training, during January 2014, enumerators went to the villages in order to elicit commercialization intentions from all cooperative members. Prior to doing so, they made sure that the leaders who had taken part in the training had held the "briefing" meeting. For each farmer group, all members who produced groundnuts for the 2014 commercialization season were asked how they intended to use their production. They had to split their anticipated harvest into (1) individual commercialization, (2) collective commercialization (via the cooperative), (3) inventories, and (4) other uses. They were told that the purpose of this survey was to better understand their decisions with regard to groundnut production. They were also informed that a subsequent group meeting would be held, where a message would be delivered to them. They were thus invited to attend that meeting.

The 79 groups were allocated to one of four conditions, depending on the information that would be disclosed in the subsequent meeting (Table 3 summarizes the RCT design): ${ }^{14}$

- In Condition A (the control group), members' intentions were not revealed. Enumerators announced that a follow-up survey would be conducted after the end of the commercialization period. This was also announced in Conditions B, C, and D.

- In Condition B, members' aggregate intentions were revealed.

- In Condition C, members' aggregate intentions as well as the distribution of intentions among members were revealed. I.e., how many members intended to contribute $100 \mathrm{~kg}$;

\footnotetext{
${ }^{14}$ As discussed in some of the papers referenced in Section 3.2, messages have differential impacts depending on the "statistics" / content they convey. Hence, the logic for a variant of information treatments.
} 
how many intended to contribute $200 \mathrm{~kg}$, and so on. This was most comparable to the CCG in the LFEs.

- In Condition D, the same information as in $\mathrm{C}$ was revealed, but the distribution of intentions was disaggregated by ordinary members versus cooperative leaders (defined as all members of the management committee which typically comprises 8 to 12 individuals). This treatment was inspired by the literature on leadership, which emphasizes that leaders' actions can have larger effects than that of regular members, in part because they are perceived as having privileged access to information (see for example Hermalin, 1998; Potters et al., 2007; Jack and Recalde, 2015).

\subsection{Sample description}

Table 4 describes the characteristics of individuals who responded to the RCT-related survey and compares means across groups that received no information about others' intentions and groups that did. Consistent with the context described in Section 2, our sample essentially comprises small farmers, with a total farm size of less then five hectares on average. The full sample cultivates groundnuts, but 58\% also produce other crops. Groundnut production is also relatively small in magnitude, with the previous and current year's average expected harvest below 1.7 tons. $84 \%$ of the farmers indicate that they intend to sell some of their groundnut harvest through the group in the upcoming commercialization season. On average, intended sales through the group amounted to $60 \%$ of farmers' production.

Overall, Table 4 does not show clear differences on pre-intervention characteristics across the two samples. There are, however, indications that generosity (as measured by a hypothetical dictator game) is higher on average for groups where no information was revealed. For a comparable groundnut-producing sample, Bernard et al. (2014) find that altruism is negatively related to group sales. So, in this case that might translate into an upward bias of the information effect. They find, however, that the associated coefficient is quite small in magnitude, in particular compared to the one associated with individuals' aversion to strategic uncertainty. As discussed below, all RCT-related estimations will control for this and other - individual characteristics that are unbalanced at baseline. Table 4 also indicates that a greater number of farmers whose group was selected to participate in the LFEs were in the control group. To the extent that participation in the LFEs affects naturally-occurring behavior - which we assess later on - this difference could also introduce some bias. Our empirical strategy therefore includes this variable among the controls. ${ }^{15}$

\footnotetext{
${ }^{15}$ Table A3 reports the same set of tests across conditions A, B, C, and D. The results are similar.
} 


\subsection{Empirical strategy}

With the LFE and RCT protocols being comparable, we rely on a common estimation strategy to assess the impact of others' intentions on the decision to contribute production/resources to the group. Individuals are indexed by subscript $i$ and groups by subscript $g$ - where "groups" refers to experimental sessions in the LFEs and day-to-day cooperatives in the RCT. Our basic estimation is as follows:

$$
A_{i g}=\alpha+\beta I_{g}+\varepsilon_{i g}
$$

where being exposed to others' intentions, which varies at the group level, is captured by a binary variable $I_{g}$ (our proxy for $A^{\prime}$ in Section 3.1), and the associated parameter $\beta$ measures its effect on the dependent variable of interest (more below). $\varepsilon_{i g}$ is a composite error term defined as: ${ }^{16}$

$$
\varepsilon_{i g}=\mu_{g}+\xi_{i g}
$$

where $\mu_{g}$ is a group-specific error and $\xi_{i g}$ is the remaining idiosyncratic one. With group members' decisions to contribute to the group being strategic complements, we allow for within-group, individual errors to be correlated. Thus, all our standard errors are clustered at the group-level. ${ }^{17}$

While the same estimator is used for both the LFEs and the RCT, interpretation of the coefficients differs across the two. In LFE-related estimates, the $\beta$ parameter is the treatment effect on the treated. In fact, all individuals selected to participate in the game did participate and no one left before all rounds were completed (although that was allowed if they wanted to). In the RCT however, only $59 \%$ of group members attended the meeting in which aggregate intentions were revealed (see last row of Table 4). Without exogenous variation in attendance to the meeting, we estimate equation 1 on the full sample of farmers, regardless of whether or not they attended. The estimated $\beta$ parameter therefore captures our "intent" to reveal or not aggregate intentions; i.e., an intent-to-treat effect. ${ }^{18}$

Although we do not find evidence of major imbalances across conditions, we augment equation 1 with a vector of individual characteristics, $X_{i g}$, to both account for existing

\footnotetext{
${ }^{16}$ In the estimating equations that follow, $\varepsilon_{i g}$ will vary depending on the specification. But, for simplicity we keep the same notation.

${ }^{17}$ We rely on the cluster-correlated Huber-White covariance matrix method to compute cluster-robust standard errors. While our design includes a reasonably large number of clusters, we also computed standard errors based on more conservative randomized inference tests. Results are available upon request, and similar to those reported here.

${ }^{18}$ One could attempt to recover the impact on those who participated in the meeting by dividing the $\beta$ estimate by the meeting participation rate. However, this would implicitly assume that the information provided in the meeting was not shared with non-attending group members, which we cannot guarantee.
} 
imbalances and enhance the precision of our estimates through reduced unexplained variance in our outcome variable. In LFE-related estimates, this vector of covariates includes the individual's age, sex, land size, education (dummy for going to a French school versus a Koranic or no schooling), and measures for risk, time (patience), and social preferences (generosity/altruism). ${ }^{19}$ In RCT-related estimates, this includes the individual's age, sex, a dummy for whether the individual holds a leadership position in the group, the groundnut harvest (in kg), a dummy for whether the farmer produced other crops, land size, measures for risk, time, and social preferences, and participation in the LFEs. This leads to the following estimating equation:

$$
A_{i g}=\alpha+\beta I_{i g}+X_{i g}^{\prime} \rho+\varepsilon_{i g}
$$

Finally, in line with our framework, we test for heterogenous treatment effects with respect to group size by estimating equation 3 , where $S_{g}$ is a dummy for large groups $(N=$ $20)$ in the LFE estimations and actual group size in the RCT estimations; $\beta$ is the average effect of being exposed to aggregate intentions among all individuals in the sample; and $\delta$ captures the additional effect of this exposure for individuals in larger groups.

$$
A_{i g}=\alpha+\beta I_{g}+\gamma S_{g}+\delta I_{g} \times S_{g}+X_{i g}^{\prime} \rho+\varepsilon_{i g}
$$

For our main specifications, we estimate the effect of revealing aggregate intentions on both the extensive margin - with the dependent variable $A_{i g}$ being a dummy for whether the individual contributed any amount to the group - and the intensive margin - where the dependent variable $A_{i g}$ is the total amount that one contributed to the group. Both are consistent with the framework (and notation) discussed in Section 3.

In the RCT-related estimates, we also run several robustness checks. First, we test for significance of $\beta$ and $\delta$ when the dependent variable is members' intentions. Because intentions were collected prior to any information revelation, we expect these parameters to be equal to 0 . Second, one may be concerned about social desirability bias in individuals' reporting of collective groundnut sales. For both the intensive and extensive margin estimates, we thus also use effective individual sales from all group members, based on the group's own administrative data (recall the booklets/cooperative records discussed in Section 4.2); although such data do not include individual characteristics, $X_{i g}$. Third, we also run some

\footnotetext{
${ }^{19}$ Generosity/social preference was elicited through a hypothetical dictator game (with a greater number indicating a more generous/altruistic individual). Risk preferences were elicited through a hypothetical Binswanger (1980)-style lottery (with a lower number indicating a more risk averse individual. Finally, patience was elicited through typical, hypothetical preference-over-time questions (with a one-day front-end delay and a higher number indicating a less patient individual).
} 
Tobit (to account for null reports) and inverse hyperbolic sine transformations specifications. Finally, we correct for multiple hypothesis testing (MHT) using the Holm-Bonferroni method (see Tables 6 and 10).

\section{Results}

\subsection{Cheap talk and coordination}

Tables 5 and 6 present our main results based on specifications 2 and 3. The first two columns are for the LFEs while the remaining ones are for the RCT. Our falsification test is presented in columns 3 and 4 where the dependent variable is one's intentions to contribute to the group, collected ahead of the intervention. In columns 5 and 6 , we present the main results using data from individual surveys, while the last two columns rely on administrative data collected from the groups' books/records (recalling there are no controls in this case).

In Table 5 we assess the extensive margin - i.e., the effect of revealing others' intentions on an individual's decision to contribute part of one's resources (i.e., number of chips in the LFEs, kilograms/kgs of groundnuts in the RCT) or not to the group. We find no direct effect of revealing aggregate intentions, be it in the LFEs or in the RCT (columns 1 and 5); however, interacting with group size yields support for Hypothesis 3. In the LFEs, cheap talk (intentions) led to an 11 percentage point increase in the probability that one invests chips collectively, albeit limited to those sessions with groups of size 20 (as opposed to 10). The same is true in column 6 , where revealing intentions increases the likelihood that one sold part of one's production through the cooperative by one percentage point for each additional group member. While insignificant, the direct effect of intentions is negative (-0.04 for LFEs and -0.08 for RCT), suggesting that the cheap-talk effect on increased coordination is limited to larger groups. In comparison, no such results are found in the falsification test (column 4). Further, we can fairly confidently rule out concerns of social desirability bias in the responses, since the results are very similar when using administrative data (column 8).

Results on the intensive margin are presented in Table 6 and show a similar pattern. While we do find a direct effect of cheap talk on the quantity of chips (column 1) and groundnuts (column 5) contributed to the group, this effect is only present in larger groups for both the LFEs (column 2) and the RCT (column 6). No such relationships are found in our placebo tests (columns 3 and 4) and the administrative data yield results comparable to those based on the individual survey data (columns 7 and 8). ${ }^{20}$ We also correct for

\footnotetext{
${ }^{20}$ Results are robust to a Tobit model (Table A5) and inverse hyperbolic sine transformation (Table A6).
} 
multiple hypothesis testing (MHT) using the Holm-Bonferroni method (see adjusted p-values in square [..] brackets). The effects in the LFEs (columns 1 and 2) are no longer significant; however, the effects in the RCT persist (columns 5-8). The only exception is the direct effect of cheap talk when using administrative data, but recall that there are fewer (no) control variables in this specification, which also explains the lower $R^{2}$. Following Maniadis et al. (2014), we also calculate the post-study probability (PSP) associated with the main cheaptalk effect, i.e., the first and fifth columns of Table 6 for the LFEs and RCT respectively. Tables A7 and A8 illustrate that for low initial priors (i.e., below 0.2) the accuracy of the cheap-talk effect can be questioned. However, for moderate to high priors (i.e., above 0.2) we can be relatively confident that the main cheap-talk effect is accurate. Note that PSPs above 0.50 are indicated in bold.

Overall, Tables 5 and 6 provide support for our predictions (in particular hypothesis 3): Cheap talk (intentions) can enhance coordination in situations of strategic uncertainty and this mainly seems to occur in larger groups, where coordination is more difficult to start with. $^{21}$ While consistent with our framework and prior work on the direct effect of cheap talk on coordination (recall theoretical and lab findings referenced in Sections 1 and 3.2), these results do not line up with Feltovich and Grossman (2015) who find that the beneficial effect of cheap talk decreases as the group size increases. However, as discussed previously, their findings are based on a threshold public-good game with messages that are different from ours. In addition, their group sizes are significantly smaller. In our LFEs, 10 is small and 20 is large, while in the RCT small constitutes less than 24 and large is 24 to 91 . This compares to 2 (small) and 15 (large) in their experiments.

As previously discussed, we are unable to exogenously vary group size in the RCT. Therefore, the effect in larger groups (particularly in the RCT) may be associated with other characteristics and thus, we should be cautious in interpreting the interaction effect. We address this concern in two main ways. First, we exploit the experimental design in order to separate the effect of group size from the potentially confounding threshold effect by using data from the LFEs. Table 7 compares the group-size effect across three main specifications. Columns 1-2 use data from all LFE sessions, regardless of the threshold level required to achieve coordination. These are columns 1-2 from Table 6. Columns 3-4 use data from LFE sessions where the average (i.e., per-player) number of chips required to achieve the threshold is constant across group size. Finally, columns 5-6 use data from LFE sessions where the overall threshold is constant across group size. As mentioned in Section 4.1 , if communication is more informative in large groups, despite the average number of

\footnotetext{
${ }^{21}$ In the upper panel of Table A9, we show that these results cannot be attributed to changes in individuals' risk, time (patience), and social preferences (generosity), since those are unaffected by the RCT intervention.
} 
chips needed to surpass the threshold or the overall threshold being fixed across group size, strategic uncertainty is likely to be the main mechanism at play. Indeed, column 6 provides evidence that it is primarily about group size and its relation to strategic uncertainty. We also note that while the point estimate in column 4 is not statistically significant, it is positive and relatively large (in the order of 20 percent relative to the control group/CCG mean).

Second, Table A4 compares group characteristics across above- and below-median dayto-day group size. We find limited evidence that these groups systematically differ from one another, except for being part of different umbrella federations, which we control for in all specifications. In short, we are reasonably confident that the group size effect is mainly associated with strategic uncertainty and less so with the threshold required to achieve coordination (which can be thought of as the amount required to fulfill contracts, for example when selling to large buyers in the day-to-day environment). We exploit the impacts of revealing intentions/cheap talk in different ways (recall conditions A-D in the RCT design, Section 4.2) in Section 5.3

\subsection{Collective commercialization and farmers' income}

With the increased level of collective commercialization induced by the RCT intervention, we turn to its potential welfare effect. Specifically, we assess its impact on farmers' total income from the sale of groundnuts. This includes individual sales as well as those conducted through the cooperative. Since the intervention started shortly before the harvest, it did not affect farmers' production choices. Therefore, any effect of the intervention is mediated by a combination of (1) changes in the way farmers allocate their marketable surplus across individual versus collective sales and (2) changes in the price that may be obtained from collective sales due to greater aggregation of the product.

The results are presented in Table 8. The dependent variable is the total revenue from selling groundnuts in thousands of FCFA (1000 FCFA was approximately equivalent to US $\$ 2$ at the time of the study). ${ }^{22}$ In column 1 , we find no evidence of a direct effect of the intervention on farmers' income from groundnuts. In column 2 we extend the model to investigate whether the intervention differentially affected smaller versus larger farmers. We interact the treatment variable with the farmer's reported area of land that is dedicated to the production of groundnuts. While the direct effect of the intervention is large and positive, the

\footnotetext{
${ }^{22}$ We are unable to use the per-unit price as our dependent variable. In fact, farmers tend not to negotiate prices on a per-kilogram basis, but on the total price for a given quantity. Field work revealed that quantities collected from farmers were quite noisy and imprecise due to the lack of weighting scales for transactions that occur at the farm gate or at local markets. As such, we are unable to recover a per-unit price for those transactions conducted outside the group. Farmers are, however, able to recall how much they earned in total for each transaction
} 
coefficient associated with the interaction term is negative. In other words, larger farmers gain less from collective commercialization, in line with the existence of economies of scale in commercialization albeit with decreasing marginal returns. Finally, column 4 assesses the robustness of these findings by controlling for various individual and group characteristics. While the sign of the coefficients remain, they are no longer statistically significant. Nevertheless, the coefficient on the direct effect of the intervention does indicate that providing information on aggregate intentions led to a meaningful increase in groundnut revenues for farmers in the treatment group.

These results, combined with those in Section 5.1, point to the potential for a "coordinationbased poverty trap" that is characterized by three key facets. First, smaller (poorer) farmers have more to gain from collective commercialization. Second, collective commercialization requires a larger group of such small farmers to achieve coordination (i.e., to surpass the threshold). Third, it is more difficult to achieve coordination in larger groups. In short, it is precisely in larger groups consisting of more small farmers that coordination may be both necessary and more difficult.

\subsection{What information matters?}

In order to assess whether the content of the information had an impact, we interact the aggregate intended actions $\left(A^{\prime}\right)$ revealed by study participants with the main treatment; i.e., whether or not this information was conveyed to the group (Table 9). Higher aggregate intentions lead to higher quantities sold to the group, but only in cooperatives where such information was revealed (column 2). First, this confirms that it is not just about "collecting intentions", but also "revealing them". Second, this finding supports the view that cheap talk helps farmers overcome coordination failure by shifting their beliefs. ${ }^{23}$ One caveat to the analysis is that individual intentions and thus the aggregate, are endogenous, potentially reflecting other characteristics of the groups in question. The results are robust, however, to the inclusion of various individual and group characteristics (columns 3 and 4).

The RCT design also included variations on the type of information that was provided, which in turn allows us to explore which feature of aggregate intentions primarily enhances coordination (recall Table 3). Table 10 presents the disaggregated impact of providing information on groundnut contributions to the cooperative, by informational treatment arm. Similarly to Table 6, we correct for multiple hypothesis testing (MHT) using the HolmBonferroni method. The adjusted p-values in square [..] brackets suggests that the main results discussed below are robust, except for the direct effects estimated using administrative

\footnotetext{
${ }^{23}$ We did not explicitly elicit individual-level beliefs as that would have significantly complicated the implementation of the RCT.
} 
data (column 5). As before, our falsification tests in columns 1 and 2 show no relationship between one's intentions and the later provision of information. Results in column 3 indicate that provision of information increased group contributions in all three Conditions (B-D), although with significant differences in magnitude. In particular, while knowing others' aggregate intention leads to higher contributions (Condition B), the effect is more than two times larger in magnitude if one is also provided with the distribution of others' intentions (Condition C). ${ }^{24}$

Two potential mechanisms may be at play here. First, one may trust a given aggregate more when it originates from a large number of individuals. For example, if farmers were to find out that most of the aggregate came from one individual's intended contribution, it would be reasonable to expect that this individual would be better off selling alone. So, revealing the distribution of intentions may help individuals refine their expectations. Second, individuals in the group may exhibit interdependent preferences, with group members' payoffs entering each others' utility functions, thus giving rise to social norms of equity and fairness (e.g., Manski, 2000; Sobel, 2005). While these effects may exist even in the absence of communication, they may be particularly salient when intentions and their distributions are revealed since they can be interpreted as signaling what other players consider "the right thing to do" (see for example Bernheim, 1994). Some examples of this type of norm and information signaling are discussed by Vesterlund (2003), Gächter et al. (2010), and Hill et al. $(2012){ }^{25}$

We find a smaller effect of revealing the distribution of intentions separately for leaders versus ordinary members (Condition D) in comparison to the overall distribution (Condition C). As mentioned previously, leaders may be perceived as having superior information relative to ordinary members. In this case, that could mean that the leader for example has better knowledge of current market conditions. ${ }^{26}$ So, it may be somewhat surprising that knowing leaders' intentions leads to positive, but lower contributions to the cooperative relative to

\footnotetext{
${ }^{24}$ In addition to the information that was revealed, our treatments differed from one another in the way they were implemented. Since RCT Conditions C and D by design revealed "distributions of intentions" also, their meetings were longer than those of RCT Conditions B and A (the control group). One could argue that this extra time spent with farmers made the revealed intentions (or collective commercialization generally) more salient; thus confounding the observed impacts. However, the large effect for RCT Condition B (relative to A) suggests that there is a direct effect of the information that is provided. In practice, the meetings for $\mathrm{B}$ were less than two minutes longer than those for A. Moreover, if time spent with subjects were the main explanatory variable here, we would expect the impacts for $\mathrm{C}$ and $\mathrm{D}$ to be similar and if at all, for $\mathrm{D}$ to have a greater impact than $\mathrm{C}$, which is not the case.

${ }^{25}$ The latter study in particular discusses how a norm of reciprocity can unravel in the presence of peerplayers' actions (as opposed to signals) in a rural context similar to the one discussed here.

${ }^{26}$ Using data from 27 groundnut cooperatives in Senegal, Bernard et al. (2014) find that $75 \%$ of members believed that the management committee (i.e., leaders) had better knowledge and information than ordinary members on where to find good traders and/or current market and farm-gate prices for the region.
} 
knowing the overall distribution (Condition C).

To further unpack this finding, we conduct an analysis comparable to that in Table 9, but now by informational treatment arm (see Table A10). First, we assess whether the average amount that leaders or group ordinary members intend to sell matters. Second, we check whether leaders' intentions being greater than those of ordinary members matters. In other words, one reason why the impact of Condition D may be smaller than that of Condition $\mathrm{C}$ is because ordinary members expect leaders to contribute significantly high amounts to the group and upon learning that leaders' intentions do not match up with this, they reduce their contributions. Table A10 suggests that the results are inconsistent with the above: Information about aggregate intentions, the overall distribution, and the distribution by leaders versus ordinary members matters; however, the actual quantities revealed do not seem to matter. In other words, the findings do not support the idea that members in Condition D may have been deceived by the intentions provided/revealed by leaders.

\subsection{Participation in games and naturally-occurring behavior}

Our design further enables us to assess how participation in the LFE coordination games affected later behavior in the naturally-occurring RCT. After the LFEs, all participants were asked to provide feedback regarding the game they had played. We had made sure that the game was neutrally framed and that there was no reference to collective marketing at any point. Still, many participants indicated that the coordination setting they had been faced with closely aligned with the situation they faced when deciding whether or not to sell their groundnut harvest through the cooperative. Recall that players were randomly selected from the full list of members for their group, but that each session only gathered players who were members of the same cooperative. ${ }^{27}$ Considering the above as well as a related literature on transfer in coordination games (e.g., Cooper and Van Huyck, 2016), we hypothesize that experiencing coordination games with members of one's group may affect one's expectations vis-à-vis group members in subsequent, naturally-occurring, collaborative contexts.

We test for this in Table 11 where, in addition to the RCT treatment, we assess the impact of one's participation in the LFEs. We find no such effect in columns 1 and 2, where the dependent variable is one's intentions to commercialize collectively. In columns 3 and 4, however, we find a positive effect of participating in the LFEs, on top of the treatment

\footnotetext{
${ }^{27}$ This decision was mainly driven by the fact that cooperatives are typically defined at the village level. With villages sometimes being far apart, we thus chose to (1) organize each session in the village school and (2) avoid further complications such as communicating decisions by phone as done by Hill et al. (2012). In Table A11 we report tests for equality of characteristics between LFE participants and non-participants within groups that were selected for the LFEs. Overall, the results show that the two samples are balanced on most characteristics, except two which we control for in all related estimations.
} 
effects that were previously identified. Importantly, there is no effect at the group level (i.e., whether the cooperative was selected for the LFEs), but there is a clear effect for whether the individual was (randomly) selected for participation in the LFEs. In fact, the results hold even when restricting our sample to only those cooperatives that were selected for the LFEs. Furthermore, this effect is independent of the treatment: In column 7, we restrict our sample to those cooperatives selected for the LFEs, but that belonged to the control group in the RCT (where no intentions were revealed). The effects are large in magnitude, with participation in the LFEs leading to an additional $74 \mathrm{kgs}$ of groundnuts being contributed to the cooperative during the (naturally-occurring) commercialization season.

In summary, while the LFEs are a useful diagnostic tool to test our hypotheses in a highly controlled environment, they seem to be more than just that. In our setting, participation in the LFEs seems to improve farmers' understanding of the strategic complementarities that exist, which in turn impacts collective commercialization. Alternatively, participation in the games may have "fine-tuned" selected farmers' expectations about fellow group members' subsequent behavior. Similar findings have been documented by Cardenas and Carpenter (2005) and Turiansky (2017) and are consistent with arguments in favor of classroom experiments (see for example a series of papers by Charles Holt and co-authors in Journal of Economic Perspectives in the late 1990s), all of which support the case for potential learning through lab experiments/LFEs. Our findings also contribute to the literature on generalizability of (lab) experiments (see for example Levitt and List, 2007; Al-Ubaydli and List, 2013; Camerer, 2015; Viceisza, 2016, and the references within) and a growing set of studies that combine findings from a spectrum of field experiments (see for example Barr et al., 2010; Finan and Schechter, 2012; Stoop et al., 2012; Hoel et al., 2017).

\section{Conclusions}

This paper reports a two-tier study that tests select drivers of coordination among members of farmer cooperatives (groundnut producers) in rural Senegal. We rely on (1) coordination games (i.e., artefactual lab-in-the-field experiments) in which we can exogenously vary all parameters of interest and (2) a naturally-occurring randomized controlled trial (i.e., a natural field experiment) where we cannot exogenously manipulate all parameters but that more immediately points to policy. The main drivers tested across the two types of experiments are (1) the presence of cheap talk/communication (in the form of members' revelation of intended contributions/sales to the group prior to play/commercialization) and (2) its interaction with the group's size (an interaction that remains underexplored according to for example Feltovich and Grossman, 2015). 
Consistent with our framework and select prior literature, we find the following:

1. Cheap talk seems to increase coordination (specifically, sales through the cooperative), but primarily in larger groups. By exploiting the two-tier nature of our experimental design, we are able to say with reasonable confidence that this group-size effect is primarily the result of reduced strategic uncertainty due to the presence of cheap talk. We also find that the content of cheap talk matters. For example, knowing the distribution of intentions leads to higher coordination than knowing the mere sum of intentions, possibly in line with the literatures on conformity and interdependent preferences. Moreover and perhaps more surprisingly, knowing the distribution of leaders' intentions (versus that of ordinary members) yields somewhat lower impacts on coordination than knowing the overall distribution.

These findings are relatively robust to (1) the use of different datasets (i.e., farmer self-reports in surveys as well as administrative booklets collected by farmer cooperatives/groups); (2) several falsification tests that assess the effect of the intervention on (a) individuals' intentions collected prior to such intervention and (b) behavioral measures that should not be impacted by the treatment; and (3) corrections for multiple hypothesis testing.

2. There is suggestive evidence that revelation of intentions leads to higher revenues from groundnut sales for smaller farmers. This is in line with certain policies to promote collective commercialization in the presence of imperfect (market) competition, particularly when it concerns smaller farmers who are less able to negotiate better prices in such environments. This evidence also points to the potential for a "coordination-based poverty trap" in which coordination is more difficult where it is most needed.

3. Participation in the LFEs (i.e., lab) impacts subsequent behavior in the RCT (i.e., day-to-day environment). Those randomly selected to participate in the games were more likely to engage in collective commercialization, even though the games were neutrally framed. We hypothesize that this may be due to one or both of the following channels: (1) a "training" effect-i.e., participants better understand issues of strategic complementarities/uncertainty-and (2) an "expectation" effect-i.e., participants finetune their beliefs vis-à-vis group members when faced with day-to-day situations where strategic complementarity matters, for example collective commercialization. This finding relates to the literatures on transfer/learning and generalizability across the spectrum of (field) experiments.

We conclude with a question that may be useful for guiding future work: Given the simplicity of this intervention - i.e., collecting intentions and publicly revealing (some variants 
of) them - why did these cooperatives, and arguably others in Sub-Saharan Africa and elsewhere, not come up with this potential solution to the coordination problem on their own? In the words of Matsuyama (1997): "If the coordination problem were simple enough that even the outsider, such as the economist and the bureaucrat, would know how to solve it, it would have been taken care of a long time ago by those directly involved with the problem."

If our intervention had missed the mark by reinventing the wheel, we would not have observed relatively robust and consistent effects of cheap talk, particularly in large groups. One possible explanation is that the study was carried out by "others" in an environment that is characterized by important interpersonal ties. So, participants may have been more willing to reveal their intended actions and believe the revealed intentions than had the process been implemented by familiar peers who could have had "hidden agendas". If so, this could in part reflect some lack of management capacity in these cooperatives. Future research can continue to explore related issues.

\section{References}

Al-Ubaydli, O. and J. A. List (2013, November). On the generalizability of experimental results in economics: With a response to Camerer. Working Paper 19666, National Bureau of Economic Research.

Aldana, M., J. Ashby, G. Burpee, S. Ferris, G. Heinrich, C. Quiros, T. Remington, and K. Wilson (2007). The organization and development of farmer groups for agroenterprise: Conclusions from a CRS \& RII-CIAT study tour in Asia, Africa and Latin America. CRS internal working paper.

Ashraf, N., X. Giné, and D. Karlan (2009). Finding missing markets (and a disturbing epilogue): Evidence from an export crop adoption and marketing intervention in Kenya. American Journal of Agricultural Economics 91(4), 973-990.

Avoyan, A. and J. Ramos (2017). A road to efficiency through communication and commitment. Working paper.

Balliet, D. (2010). Communication and cooperation in social dilemmas: A meta-analytic review. Journal of Conflict Resolution 54(1), 39-57.

Barr, A., A. Zeitlin, et al. (2010). Dictator games in the lab and in nature: External validity tested and investigated in Ugandan primary schools. Technical report, Centre for the Study of African Economies, University of Oxford.

Barrett, C. B. (2008). Smallholder market participation: Concepts and evidence from eastern and southern Africa. Food Policy 33(4), 299 - 317.

Battalio, R., L. Samuelson, and J. Van Huyck (2001). Optimization incentives and coordination failure in laboratory stag hunt games. Econometrica 69(3), 749-764. 
Bergquist, L. F. (2017). Pass-through, competition, and entry in agricultural markets: Experimental evidence from Kenya. UC Berkeley Mimeograph.

Bernard, T., L. Sène, A. C. G. Viceisza, and F. Wouterse (2014). Leaders needed: Experimental evidence from rural producer organizations in Senegal. Working paper.

Bernard, T., A. S. Taffesse, and E. Gabre-Madhin (2008). Impact of cooperatives on smallholders' commercialization behavior: evidence from Ethiopia. Agricultural Economics 39(2), $147-161$.

Bernheim, B. D. (1994). A theory of conformity. Journal of Political Economy 102(5), $841-877$.

Binswanger, H. P. (1980). Attitudes toward risk: Experimental measurement in rural india. American Journal of Agricultural Economics 62(3), 395.

Blume, A. and A. Ortmann (2007). The effects of costless pre-play communication: Experimental evidence from games with pareto-ranked equilibria. Journal of Economic Theory 132(1), $274-290$.

Brandts, J. and D. J. Cooper (2006, June). A change would do you good .... an experimental study on how to overcome coordination failure in organizations. American Economic Review 96(3), 669-693.

Camerer, C. (2003). Behavioral Game Theory. Princeton, NJ: Princeton University Press.

Camerer, C. F. (2015). The promise and success of lab-field generalizability in experimental economics: A critical reply to Levitt and List. In G. Frechette and A. Schotter (Eds.), Handbook of Experimental Economic Methodology. Oxford University Press.

Cardenas, J. C. and J. P. Carpenter (2005). Three Themes on Field Experiments and Economic Development, pp. 71-123.

Casaburi, L. and R. Macchiavello (2015). Loyalty, exit, and enforcement: Evidence from a Kenya dairy cooperative. American Economic Review Papers and Proceedings 105(5), $286-90$.

Casaburi, L. and R. Macchiavello (2019, February). Demand and supply of infrequent payments as a commitment device: Evidence from Kenya. American Economic Review 109(2), $523-55$.

Casaburi, L. and T. Reed (2017). Competition in agricultural markets: An experimental approach. Working paper.

Caswell, N. (1984). Autopsie de l'ONCAD. Politique Africaine 14(June), 39-73.

Charness, G. and B. Grosskopf (2004). What makes cheap talk effective? experimental evidence. Economics Letters 83, 383-389.

Cooper, D. J. and J. Van Huyck (2016). Coordination and transfer. Working paper. 
Cooper, D. J. and R. A. Weber (2019). Recent advances in experimental coordination games. Working paper.

Cooper, R., D. V. DeJong, R. Forsythe, and T. W. Ross (1992). Communication in coordination games. Quarterly Journal of Economics 107(2), 731-771.

Crawford, V. P. (1998). A survey of experiments on communication via cheap talk. Journal of Economic Theory 78, 286-298.

Devetag, G. and A. Ortmann (2007). When and why? a critical survey on coordination failure in the laboratory. Experimental Economics 10(3), $331-344$.

Dillon, B. and C. Dambro (2017). How competitive are crop markets in Sub-Saharan Africa? American Journal of Agricultural Economics 99(5), 1344-1361.

Elfenbein, D. W., R. Fisman, and B. McManus (2018, March). Does cheap talk affect market outcomes? Evidence from eBay. Working Paper 24437, National Bureau of Economic Research.

Fafchamps, M. and R. V. Hill (2005). Selling at the farmgate or traveling to market. American Journal of Agricultural Economics 87(3), 717-734.

Farrell, J. (1987). Cheap talk, coordination, and entry. Rand Journal of Economics 18, $34-39$.

Farrell, J. and M. Rabin (1996). Cheap talk. Journal of Economic Perspectives 10(3), $103-118$.

Feltovich, N. and P. J. Grossman (2015). How does the effect of pre-play suggestions vary with group size? Experimental evidence from a threshold public-good game. European Economic Review $79(\mathrm{C})$, 263-280.

Finan, F. and L. Schechter (2012). Vote-buying and reciprocity. Econometrica 80(2), 863881.

Gächter, S., D. Nosenzo, E. Renner, and M. Sefton (2010). Sequential vs. simultaneous contributions to public goods: Experimental evidence. Journal of Public Economics 94(7), $515-522$.

Goeree, J. and C. Holt (2002). Coordination games. Volume 2 of Encyclopedia of Cognitive Science, pp. 204?208. London: Nature Publishing Group, McMillan.

Harrison, G. W. and J. A. List (2004). Field experiments. Journal of Economic Literature $42(4), 1009-1055$.

Heinemann, H., R. Nagel, and P. Ockenfels (2009). Measuring strategic uncertainty in coordination games. The Review of Economic Studies 76(1), 181-221.

Hellin, J., M. Lundy, and M. Meijer (2007). Farmer organization, collective action and market access in Meso-America. CAPRi Working Paper 67. 
Hermalin, B. E. (1998). Toward an economic theory of leadership: Leading by example. American Economic Review, 1188-1206.

Hill, R., E. Maruyama, M. Olapade, and M. Frölich (2014). Strengthening producer organizations to increase market access of smallholder farmers in Uganda. Working paper.

Hill, R. V., E. Maruyama, and A. Viceisza (2012). Breaking the norm: An empirical investigation into the unraveling of good behavior. Journal of Development Economics 99(1), $150-162$.

Hoel, J. B., M. Hidrobo, T. Bernard, and M. Ashour (2017). Productive inefficiency in dairy farming and cooperation between spouses: Evidence from Senegal. IFPRI discussion paper 1698.

Hoff, K. (2001). Beyond Rosenstein-Rodan: The modern theory of coordination problems in development. In Proceedings of the Annual World Bank Conference on Development Economics, 2000, pp. 145-188. Washington DC: World Bank.

Jack, B. K. and M. P. Recalde (2015). Leadership and the voluntary provision of public goods: Field evidence from Bolivia. Journal of Public Economics 122, 80-93.

Kets, W. and A. Sandroni (2017). A theory of strategic uncertainty and cultural diversity. Working paper.

Key, N., E. Sadoulet, and A. D. Janvry (2000). Transactions costs and agricultural household supply response. American Journal of Agricultural Economics 82(2), 245-259.

Levitt, S. D. and J. A. List (2007). What do laboratory experiments measuring social preferences reveal about the real world? The Journal of Economic Perspectives 21, 153174.

Maniadis, Z., F. Tufano, and J. A. List (2014, January). One swallow doesn't make a summer: New evidence on anchoring effects. American Economic Review 104 (1), 277-90.

Manski, C. F. (2000). Economic analysis of social interactions. The Journal of Economic Perspectives 14 (3), 115-136.

Matsuyama, K. (1997). Economic development as coordination problems. The Role of Government in East Asian Economic Development, 134-160.

Ochs, J. (1995). Chapter 3: Coordination problems. Handbook of Experimental Economics. Princeton, NJ: Princeton University Press.

Potters, J., M. Sefton, and L. Vesterlund (2007). Leading-by-example and signaling in voluntary contribution games: an experimental study. Economic Theory, 169-182.

Ragasa, C. and J. Golan (2014). The role of rural producer organizations for agricultural service provision in fragile states. Agricultural Economics 45(5), 537-553. 
Rapoport, A. and D. A. Seale (2008). Chapter 34 coordination success in non-cooperative large group market entry games. Volume 1 of Handbook of Experimental Economics Results, pp. 273 - 295. Elsevier.

Rosenstein-Rodan, P. N. (1943). Problems of industrialisation of eastern and south-eastern europe. The Economic Journal 53(210/211), 202-211.

Sobel, J. (2005). Interdependent preferences and reciprocity. Journal of economic literature $43(2), 392-436$.

Stoop, J., C. N. Noussair, and D. van Soest (2012). From the lab to the field: Cooperation among fishermen. Journal of Political Economy 120(6), 1027-1056.

Turiansky, A. (2017). Collective action in games as in life: Experimental evidence from canal cleaning in Haiti. Mathematica Policy Research Report.

Van Huyck, J. and R. Battalio (2008). Chapter 51 coordination failure in market statistic games. Volume 1 of Handbook of Experimental Economics Results, pp. 454 - 462. Elsevier.

Van Huyck, J. B., R. C. Battalio, and R. O. Beil (1990). Tacit coordination games, strategic uncertainty, and coordination failure. American Economic Review 80.

Vesterlund, L. (2003). The informational value of sequential fundraising. Journal of Public Economics 87(3), 627-657.

Viceisza, A. C. G. (2016). Creating a lab in the field: Economics experiments for policymaking. Journal of Economic Surveys 30(5), 835-854.

Voors, M., T. Turley, A. Kontoleon, E. Bulte, and J. A. List (2012). Exploring whether behavior in context-free experiments is predictive of behavior in the field: Evidence from lab and field experiments in rural Sierra Leone. Economics Letters 114(3), 308-311.

Wydick, B. (2007). Games in Economic Development. Cambridge, UK: Cambridge University Press.

Zwane, A. P., J. Zinman, E. Van Dusen, W. Pariente, C. Null, E. Miguel, M. Kremer, D. S. Karlan, R. Hornbeck, X. Giné, E. Duflo, F. Devoto, B. Crepon, and A. Banerjee (2011). Being surveyed can change later behavior and related parameter estimates. Proceedings of the National Academy of Sciences 108(5), 1821-1826. 


\section{Tables}

Table 1: Sample distribution across RCT and LFEs

\begin{tabular}{c|lccccc}
\hline & \multicolumn{2}{|l|}{ \# of Cooperatives } & \multicolumn{2}{l}{ \# of farmers in survey } & \multicolumn{2}{l}{ farmers in admin data } \\
Was in LFEs? & No & Yes & No & Yes & No & Yes \\
\hline RCT Condition A & 10 & 7 & 114 & 80 & 320 & 207 \\
RCT Condition B & 15 & 6 & 173 & 68 & 640 & 201 \\
RCT Condition C & 14 & 6 & 160 & 59 & 360 & 276 \\
RCT Condition D & 14 & 7 & 156 & 72 & 418 & 331 \\
\hline Total & 53 & 26 & 603 & 279 & 1738 & 1015 \\
\hline
\end{tabular}

Condition A is the control group in the RCT

Conditions B, C, and D are treatment variations (see Section 4.2 or Table 3 )

Table 2: Distribution of BCG and CCG variations

\begin{tabular}{l|ccc}
\hline Variable & BCG & CCG & Total \\
\hline \# Sessions & 28 & 28 & 56 \\
\# Rounds & 112 & 110 & 222 \\
\# Players & 429 & 410 & 839 \\
\# Observations & 1716 & 1600 & 3316 \\
\hline \multicolumn{4}{c}{ BCG = Baseline Coordination Game } \\
CCG = Communication Coordination Game
\end{tabular}

Table 3: RCT treatments

\begin{tabular}{c|ccc}
\hline RCT Condition & \multicolumn{3}{|c}{ What is revealed? } \\
\hline A & - & - & - \\
B & Aggregate intentions & - & - \\
C & Aggregate intentions & Distribution & - \\
D & Aggregate intentions & Distribution & Leader vs. Member \\
\hline
\end{tabular}

In all conditions, there was a training; intentions were collected; and a survey was conducted. 


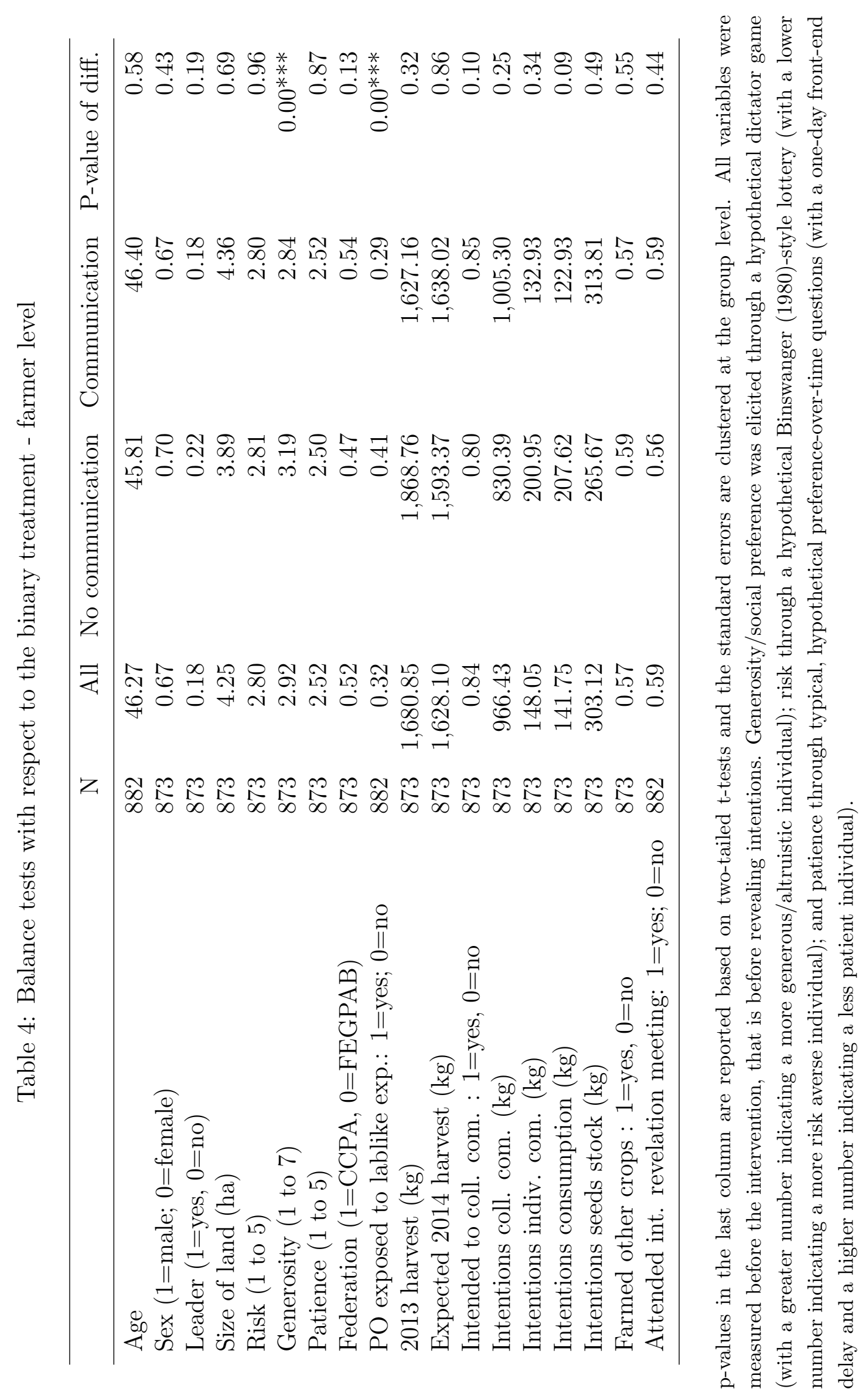




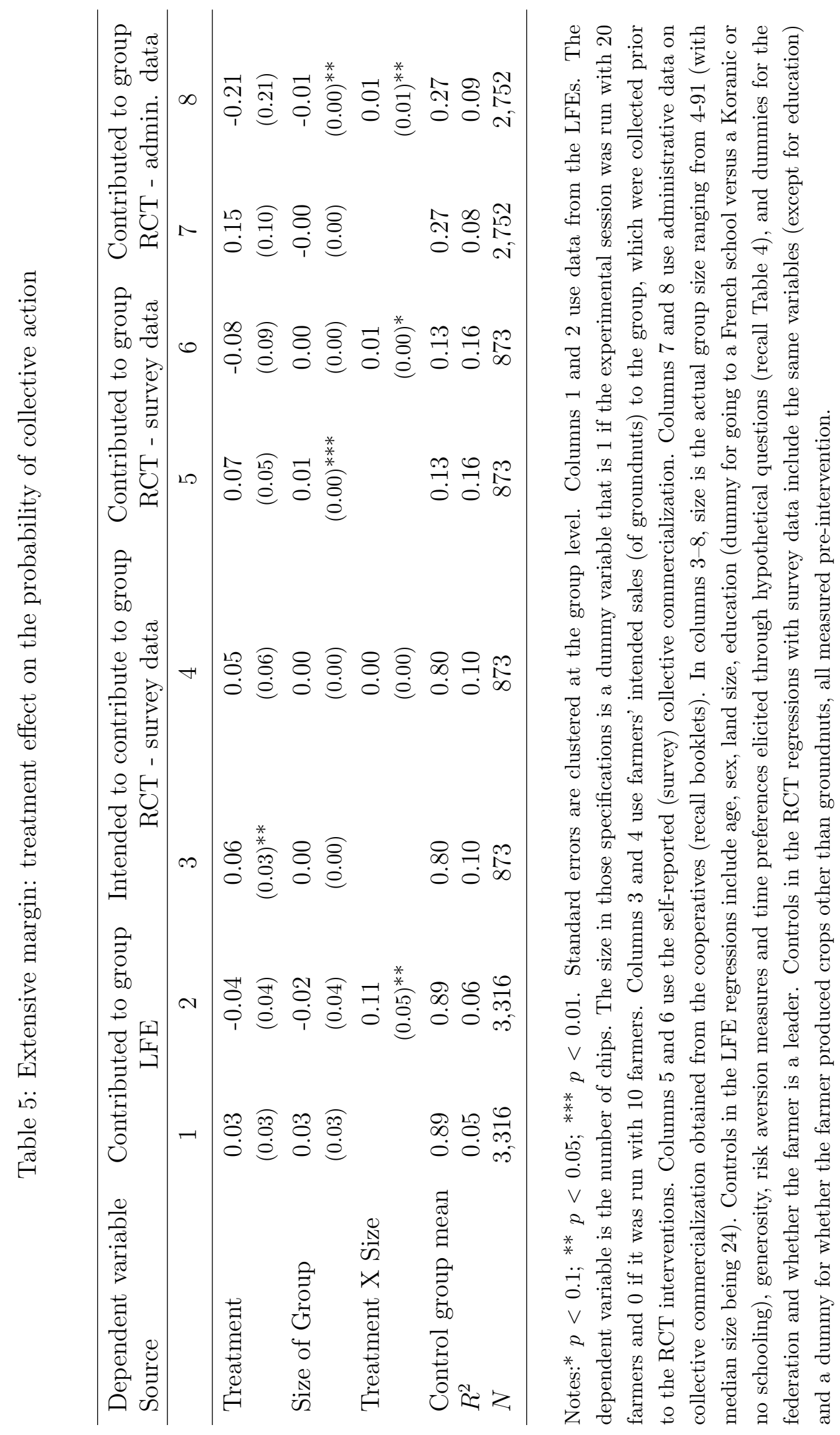







Table 7: Isolating the effect of group size from that of the threshold (LFEs)

\begin{tabular}{|c|c|c|c|c|c|c|}
\hline $\begin{array}{l}\text { Dependent variable } \\
\text { Source (recall Section 4.1) }\end{array}$ & \multicolumn{6}{|c|}{$\begin{array}{l}\text { \# Chips contributed } \\
\text { LFE }\end{array}$} \\
\hline Treatment & $\begin{array}{c}0.40 \\
(0.19)^{* *}\end{array}$ & $\begin{array}{l}-0.03 \\
(0.31)\end{array}$ & $\begin{array}{c}0.22 \\
(0.21)\end{array}$ & $\begin{array}{r}-0.03 \\
(0.30)\end{array}$ & $\begin{array}{l}0.36 \\
(0.24)\end{array}$ & $\begin{array}{r}-0.02 \\
(0.29)\end{array}$ \\
\hline Size of Group & $\begin{array}{l}0.03 \\
(0.24)\end{array}$ & $\begin{array}{l}-0.31 \\
(0.27)\end{array}$ & $\begin{array}{l}-0.27 \\
(0.21)\end{array}$ & $\begin{array}{r}-0.53 \\
(0.35)\end{array}$ & $\begin{array}{l}-0.00 \\
(0.23)\end{array}$ & $\begin{array}{l}-0.38 \\
(0.25)\end{array}$ \\
\hline Treatment X Size & & $\begin{array}{c}0.65 \\
(0.38)^{*}\end{array}$ & & $\begin{array}{c}0.53 \\
(0.41)\end{array}$ & & $\begin{array}{c}0.77 \\
(0.44)^{*}\end{array}$ \\
\hline Control group mean & \multicolumn{2}{|c|}{3.03} & \multicolumn{2}{|c|}{3.09} & \multicolumn{2}{|c|}{3.09} \\
\hline$R^{2}$ & 0.09 & 0.10 & 0.08 & 0.09 & 0.11 & 0.12 \\
\hline$N$ & 3,316 & 3,316 & 2,116 & 2,116 & 2,320 & 2,320 \\
\hline Fixed threshold? & \multicolumn{2}{|c|}{ No } & \multicolumn{2}{|c|}{ Yes - Average } & \multicolumn{2}{|c|}{ Yes - Overall } \\
\hline
\end{tabular}

Notes: $* * * p<0.01, * * p<0.05, * p<0.1$. Standard errors are clustered at the group level. All columns use data from the LFEs. The dependent variable is the number of chips. The size in all specifications is a dummy variable that is 1 if the experimental session was run with 20 farmers and 0 if it was run with 10 farmers. Columns 1 and 2 use data from all LFEs regardless of the threshold required for coordination. Columns 3 and 4 only use data from the LFEs where the average (per-player) number of chips required to reach the threshold was the same across large and small groups. Columns 5 and 6 only use data from the LFEs where the overall threshold was fixed across small and large groups. Controls in the regressions include age, sex, land size, education (dummy for going to a French school versus a Koranic or no schooling), generosity, risk aversion measures and time preferences elicited through hypothetical questions (recall Table 4 ), and dummies for the federation and whether the farmer is a leader. 
Table 8: Effect on revenues from groundnut sales

\begin{tabular}{lcccc}
\hline $\begin{array}{l}\text { Dependent variable } \\
\text { Source }\end{array}$ & \multicolumn{5}{c}{ Revenues from groundnut sales (FCFA) } \\
RCT - survey data \\
\hline Treatment & 15.57 & 185.11 & 7.91 & 61.05 \\
& $(73.25)$ & $(56.22)^{* * *}$ & $(51.46)$ & $(39.07)$ \\
Size of land (ha) & 3.48 & 45.62 & 0.85 & 14.28 \\
& $(3.55)$ & $(20.68)^{* *}$ & $(1.16)$ & $(16.38)$ \\
Treatment X Land size (ha) & \multicolumn{5}{c}{-43.33} \\
\multicolumn{5}{c}{$(20.83)^{* *}$} \\
Control group mean \\
$R^{2}$ & 0.01 & 0.06 & -13.70 \\
$N$ & 868 & 868 & 0.34 & $(16.47)$ \\
Controls & No & No & Yes & 868 \\
& \multicolumn{5}{c}{ Yes } \\
\hline
\end{tabular}

Notes: $* p<0.1 ; * * p<0.05 ; * * * p<0.01$. Standard errors are clustered at the group level. The dependent variable in all the regressions is the total revenue from selling groundnuts in thousands of FCFA (1000 FCFA was approximately equivalent to US $\$ 2$ at the time of the study). The last column adds as control variables age, sex, land size, generosity, risk aversion and time preference (recall Table 4), cooperative size, dummies for the federation, whether the farmer is a leader, and whether the farmer produced crops other than groundnuts, all measured pre-intervention, as well as a dummy for whether the farmer indicated positive intentions to sell through the group. 
Table 9: Collective commercialization and aggregate intentions

\begin{tabular}{lcccc}
\hline Dependent variable & \multicolumn{5}{c}{ Contributed to group } \\
Source & 91.90 & -16.87 & 121.66 & 50.55 \\
Treatment & $(37.79)^{* *}$ & $(36.80)$ & $(34.92)^{* * *}$ & $(35.13)$ \\
& 3.41 & -0.49 & 0.58 & -1.83 \\
Aggregate intentions (tonnes) & $(1.08)^{* * *}$ & $(0.51)$ & $(1.46)$ & $(1.29)$ \\
& \multicolumn{5}{c}{4.59} & & 2.96 \\
Treatment X Aggregate intentions & $(1.42)^{* * *}$ & & $(1.44)^{* *}$ \\
& \multicolumn{5}{c}{39.58} \\
Control group mean & 0.08 & 0.10 & 0.17 & 0.18 \\
$R^{2}$ & 873 & 873 & 873 & 873 \\
$N$ & No & No & Yes & Yes \\
Controls? & \multicolumn{5}{c}{. }
\end{tabular}

Notes: ${ }^{*} p<0.1{ }^{* *} p<0.05$; ${ }^{* * *} p<0.01$. Standard errors are clustered at the group level. The dependent variable is the quantity of groundnuts sold through the group. Aggregate intentions (in tonnes) are obtained as the sum of the individual intentions reported by farmers. Controls include age, sex, land size, generosity, risk aversion measures and time preferences elicited through hypothetical questions (recall Table 4), cooperative size, and dummies for the federation, whether the farmer is a leader, and whether the farmer produced crops other than groundnuts, all measured pre-intervention. A dummy for whether the individual indicated positive intentions to sell through the group is also added. 


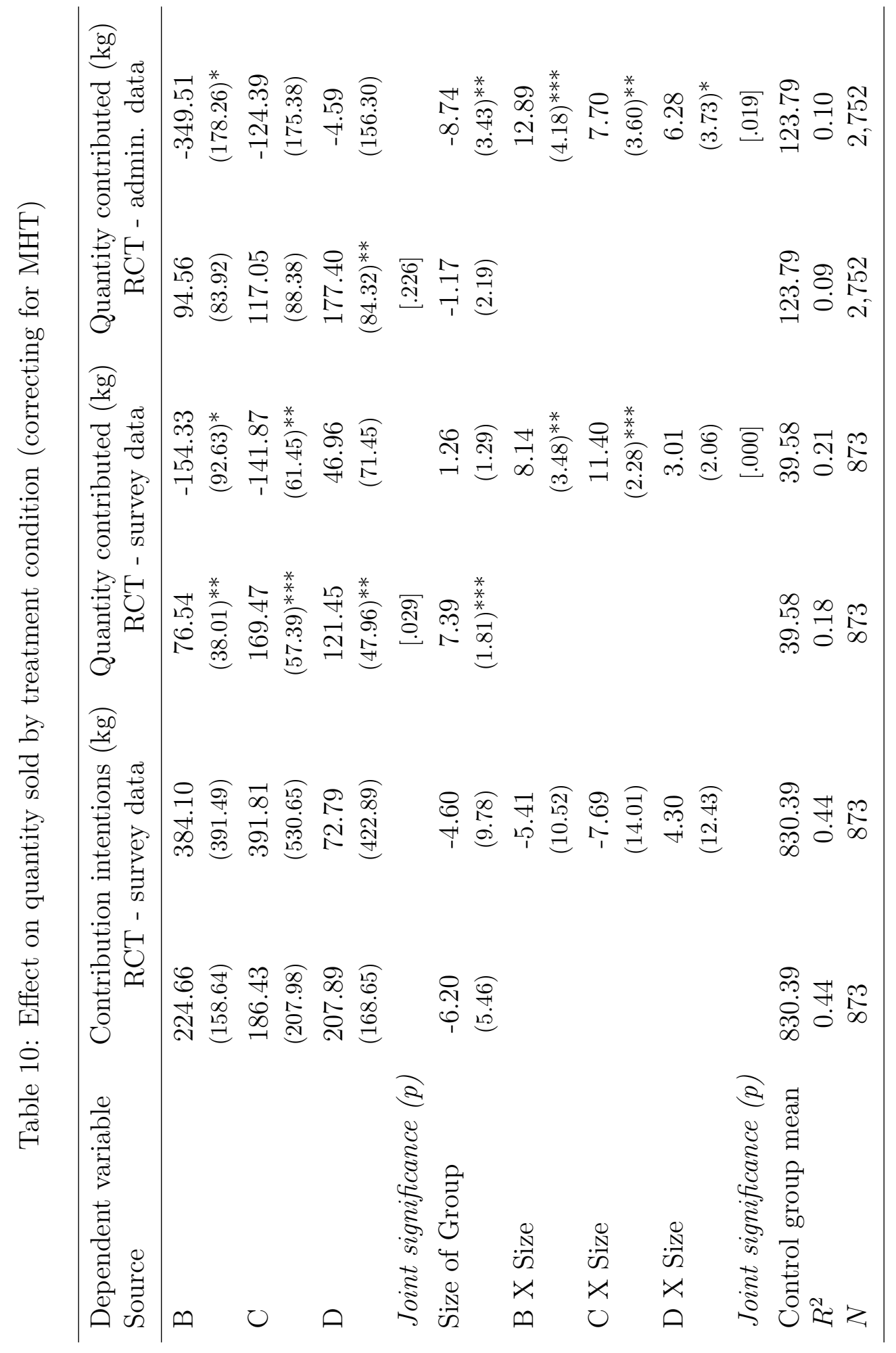

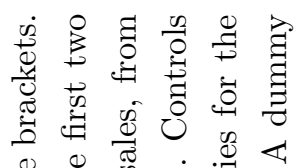

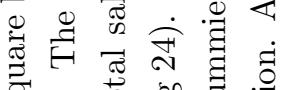

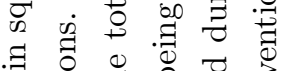
当 \&

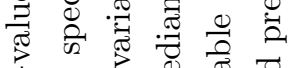
立

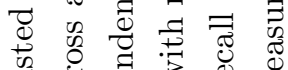



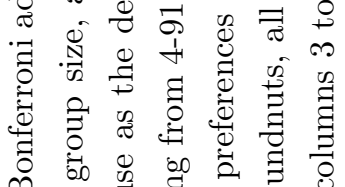

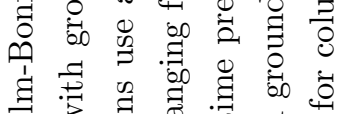

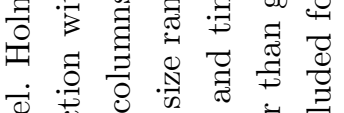

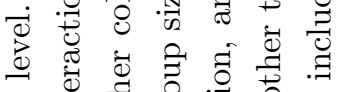

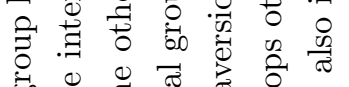
क人

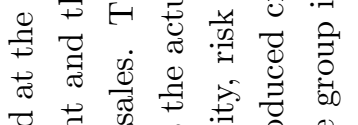
ठ

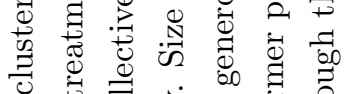

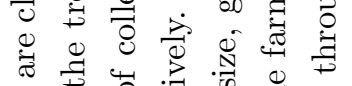

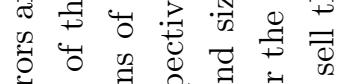

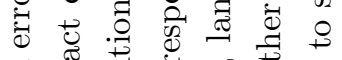
芯苛离



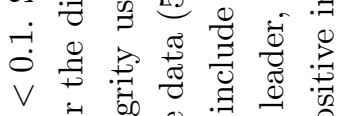
*

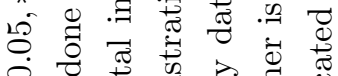

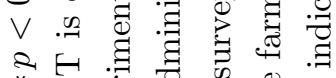
*

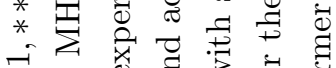

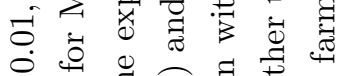
$\checkmark$ व *

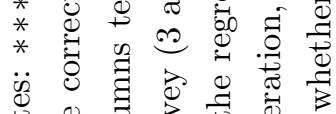

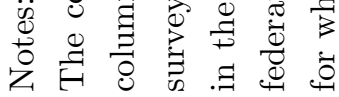




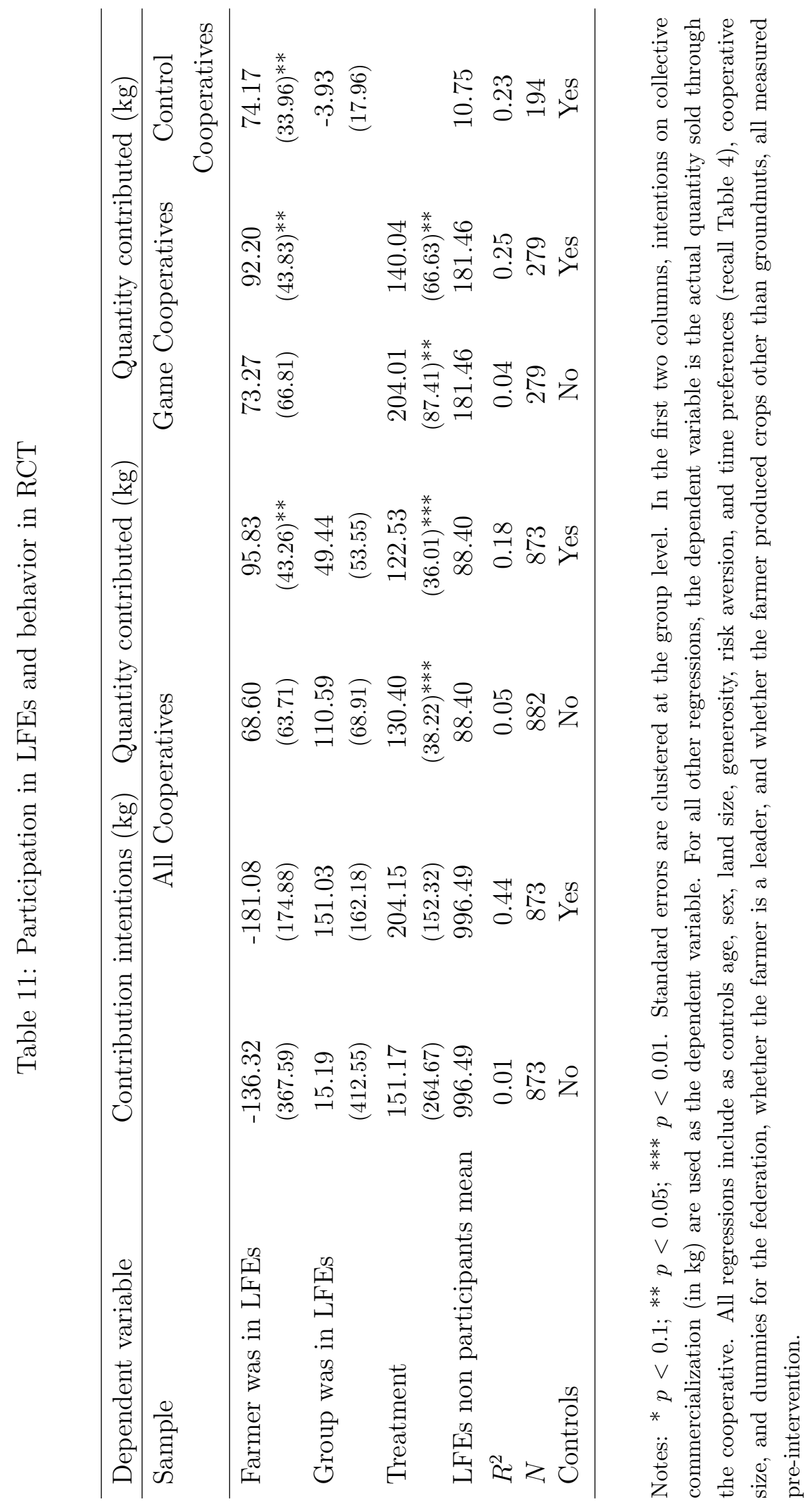




\section{Appendix}

Figure A1: LFEs, visual aids

\begin{tabular}{|c|c|ccc|c|c|c|}
\hline$N: 10,20$ & \multicolumn{1}{|c|}{ Intention board } \\
\hline
\end{tabular}

Table A1: Distribution of $N, T, H$ and uncertainty variations in LFEs

\begin{tabular}{|c|c|c|c|c|c|c|c|c|c|c|}
\hline Variable & \multicolumn{2}{|c|}{$N$} & \multicolumn{4}{|c|}{$T$} & \multicolumn{2}{|c|}{$H$} & \multicolumn{2}{|c|}{ Uncertainty } \\
\hline & 10 & 20 & 40 & 50 & 80 & 100 & 2,500 & 3,000 & yes & no \\
\hline Variation at & Sessic & a level & & Round & evel & & Roun & I level & Session & a level \\
\hline Sessions & 28 & 28 & 56 & 56 & 56 & 56 & 56 & 56 & 28 & 28 \\
\hline Rounds & 112 & 110 & 86 & 86 & 24 & 26 & 111 & 111 & 108 & 114 \\
\hline Observations & 1,120 & 2,196 & 1,160 & 1,160 & 478 & 518 & 1,658 & 1,658 & 1,720 & 1,596 \\
\hline
\end{tabular}

Table A2: Correlation between parameter variations in LFEs

\begin{tabular}{l|ccccc}
\hline Variable & CCG & $N$ & $T$ & $H$ & Uncertainty \\
\hline CCG & 1.00 & & & & \\
$N$ & -0.08 & 1.00 & & & \\
$T$ & -0.05 & $0.51^{*}$ & 1.00 & & \\
$H$ & 0.00 & 0.00 & 0.00 & 1.00 & \\
Uncertainty & 0.04 & -0.02 & -0.01 & -0.00 & 1.00 \\
\hline
\end{tabular}

$\mathrm{CCG}=$ communication coordination game.

* Significantly different from 0 at the $10 \%$ level. 


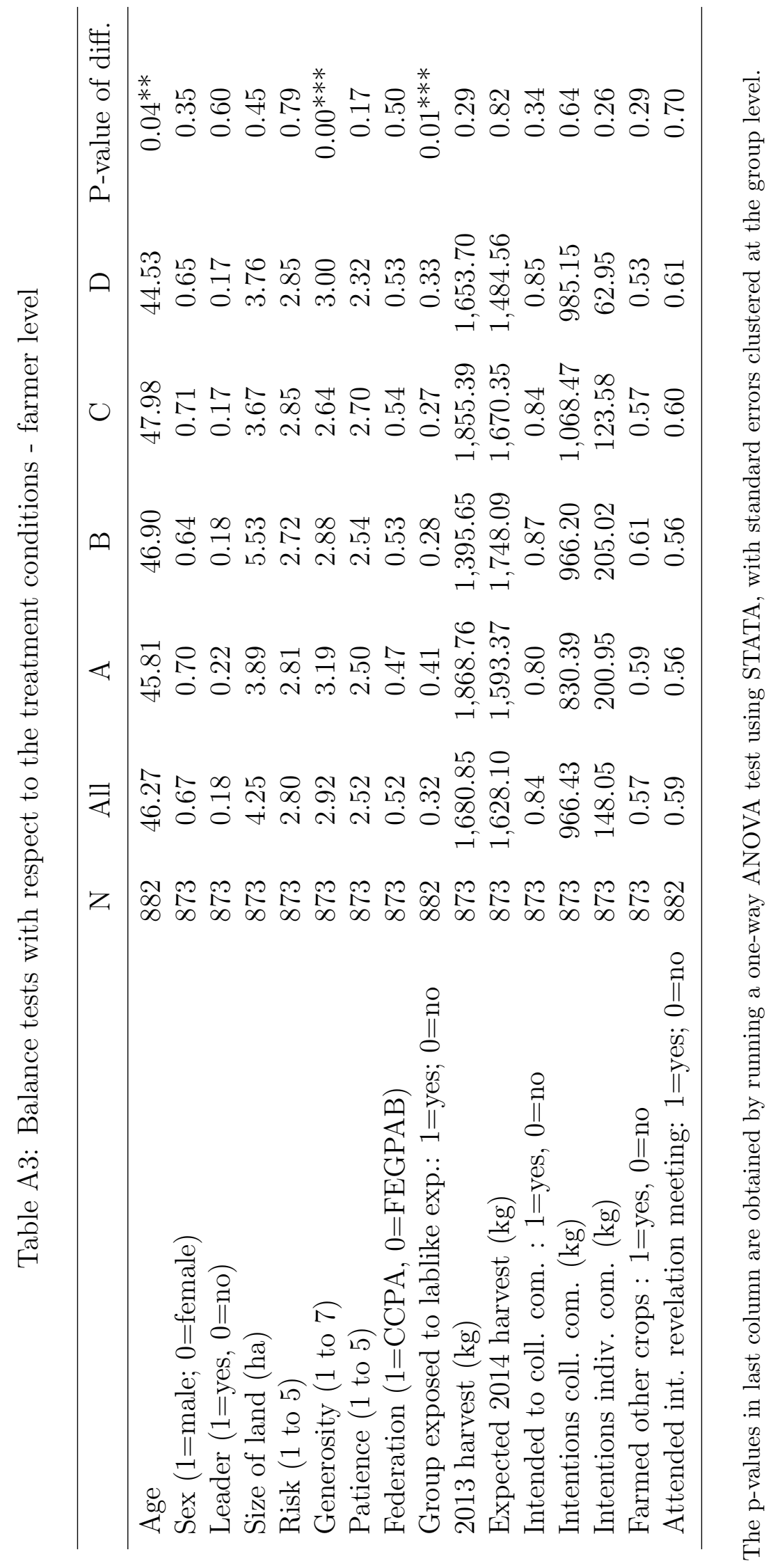




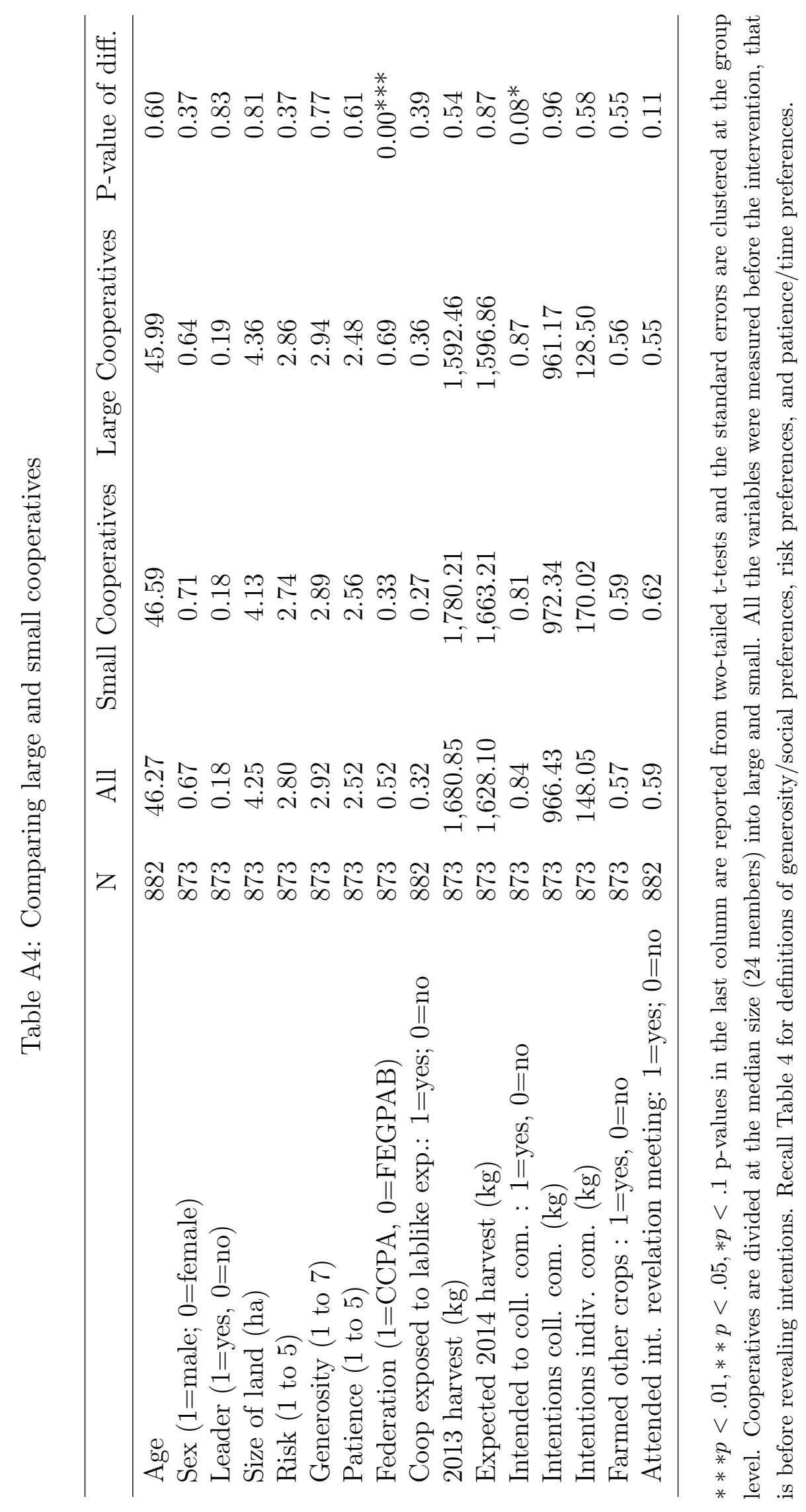


Table A5: Effect on collective commercialization - Tobit model

\begin{tabular}{lcccc}
\hline $\begin{array}{l}\text { Dependent variable } \\
\text { Source }\end{array}$ & \multicolumn{5}{c}{$\begin{array}{c}\text { Contributed to group } \\
\text { RCT - survey data }\end{array}$} \\
\hline Treatment & 278.60 & -622.40 & 460.23 & -88.53 \\
& $(295.31)$ & $(550.79)$ & $(258.33)^{*}$ & $(512.10)$ \\
Size of Group & 27.50 & -2.87 & 25.79 & 7.97 \\
& $(6.20)^{* * *}$ & $(15.59)$ & $(6.50)^{* * *}$ & $(15.38)$ \\
Treatment X Size & \multicolumn{5}{c}{31.70} & & 18.94 \\
& \multicolumn{5}{c}{$(16.94)^{*}$} & $(16.57)$ \\
Control group mean & \multicolumn{5}{c}{39.58} & \\
Pseudo $R^{2}$ & 0.03 & 0.03 & 0.04 & 0.04 \\
$N$ & 882 & 873 & 873 & 873 \\
Control & No & No & Yes & Yes \\
\hline
\end{tabular}

Notes: ${ }^{*} p<0.1{ }^{* *} p<0.05$; ${ }^{* *} p<0.01$. The table shows the estimations of the main equation of interest (collective commercialization on treatment) using a Tobit model for the null quantities reported. The dependent variable is the quantity of groundnuts sold through the group. Controls include age, sex, land size, generosity, risk aversion measures and time preferences elicited through hypothetical questions (recall Table 4), and dummies for the federation, whether the farmer is a leader, and whether the farmer produced crops other than groundnuts, all measured pre-intervention. A dummy for whether the individual indicated positive intentions to sell through the group is also added. 
Table A6: Effect on collective commercialization - inverse hyperbolic sine transformation

\begin{tabular}{lcccc}
\hline $\begin{array}{l}\text { Dependent variable } \\
\text { Source }\end{array}$ & \multicolumn{5}{c}{$\begin{array}{c}\text { Contributed to group } \\
\text { RCT - survey data }\end{array}$} \\
\hline Treatment & 0.42 & -1.13 & 0.64 & -0.52 \\
& $(0.39)$ & $(0.68)$ & $(0.34)^{*}$ & $(0.63)$ \\
Size of Group & 0.05 & -0.00 & 0.05 & 0.01 \\
& $(0.01)^{* * *}$ & $(0.02)$ & $(0.01)^{* * *}$ & $(0.02)$ \\
Treatment X Size & \multicolumn{5}{c}{0.06} & 0.04 \\
& \multicolumn{5}{c}{$(0.02)^{* *}$} & $(0.02)^{*}$ \\
Control group mean & 0.10 & 0.11 & 0.17 & 0.17 \\
$R^{2}$ & 882 & 873 & 873 & 873 \\
$N$ & No & No & Yes & Yes \\
Control & $* p<0.1 ;{ }^{* *} p<0.05 ; * * * p<0.01$ &
\end{tabular}

Notes: ${ }^{*} p<0.1 ;{ }^{* *} p<0.05 ;{ }^{* * *} p<0.01$. Standard errors are clustered at the group level. The dependent variable is the quantity of groundnuts sold through the group, transformed by the inverse hyperbolic sine. Controls include age, sex, land size, generosity, risk aversion measures and time preferences elicited through hypothetical questions (recall Table 4), and dummies for the federation, whether the farmer is a leader, and whether the farmer produced crops other than groundnuts, all measured pre-intervention. A dummy for whether the individual indicated positive intentions to sell through the group is also added.

Table A7: PSP estimates: LFE cheap-talk effect in Table 6 - column $1(\beta=0.66)$

\begin{tabular}{llllll}
\hline & $k=1$ & $k=2$ & $k=5$ & $k=10$ & $k=15$ \\
$\pi$ & & & & & \\
\hline 0.01 & 0.118 & 0.084 & 0.043 & 0.025 & 0.018 \\
0.02 & 0.212 & 0.156 & 0.082 & 0.048 & 0.037 \\
0.05 & 0.410 & 0.323 & 0.188 & 0.116 & 0.089 \\
0.1 & $\mathbf{0 . 5 9 5}$ & $\mathbf{0 . 5 0 2}$ & 0.328 & 0.217 & 0.172 \\
0.2 & $\mathbf{0 . 7 6 7}$ & $\mathbf{0 . 6 9 4}$ & $\mathbf{0 . 5 2 4}$ & 0.384 & 0.318 \\
0.3 & $\mathbf{0 . 8 5 0}$ & $\mathbf{0 . 7 9 5}$ & $\mathbf{0 . 6 5 3}$ & $\mathbf{0 . 5 1 6}$ & 0.444 \\
0.35 & $\mathbf{0 . 8 7 7}$ & $\mathbf{0 . 8 3 0}$ & $\mathbf{0 . 7 0 3}$ & $\mathbf{0 . 5 7 3}$ & $\mathbf{0 . 5 0 1}$ \\
0.55 & $\mathbf{0 . 9 4 2}$ & $\mathbf{0 . 9 1 7}$ & $\mathbf{0 . 8 4 3}$ & $\mathbf{0 . 7 5 3}$ & $\mathbf{0 . 6 9 5}$ \\
\hline
\end{tabular}

Note: $P S P=\frac{\left(1-\beta^{k}\right) \pi}{\left(1-\beta^{k}\right) \pi+\left[1-(1-\alpha)^{k}\right](1-\pi)}$, where:

typical power $=1-\beta, \quad \alpha=0.05, \quad \pi=$ a prior

$k$ represents the number of independent researchers

working on specific associations in a field

(i.e., competition) 
Table A8: PSP estimates: RCT cheap-talk effect in Table 6 - column $5(\beta=0.99)$

\begin{tabular}{llllll}
\hline & $k=1$ & $k=2$ & $k=5$ & $k=10$ & $k=15$ \\
$\pi$ & & & & & \\
\hline 0.01 & 0.167 & 0.094 & 0.043 & 0.025 & 0.018 \\
0.02 & 0.288 & 0.173 & 0.083 & 0.048 & 0.037 \\
0.05 & $\mathbf{0 . 5 1 0}$ & 0.351 & 0.189 & 0.116 & 0.089 \\
0.1 & $\mathbf{0 . 6 8 8}$ & $\mathbf{0 . 5 3 3}$ & 0.329 & 0.217 & 0.172 \\
0.2 & $\mathbf{0 . 8 3 2}$ & $\mathbf{0 . 7 1 9}$ & $\mathbf{0 . 5 2 5}$ & 0.384 & 0.318 \\
0.3 & $\mathbf{0 . 8 9 5}$ & $\mathbf{0 . 8 1 5}$ & $\mathbf{0 . 6 5 5}$ & $\mathbf{0 . 5 1 6}$ & 0.444 \\
0.35 & $\mathbf{0 . 9 1 4}$ & $\mathbf{0 . 8 4 7}$ & $\mathbf{0 . 7 0 4}$ & $\mathbf{0 . 5 7 3}$ & $\mathbf{0 . 5 0 1}$ \\
0.55 & $\mathbf{0 . 9 6 0}$ & $\mathbf{0 . 9 2 6}$ & $\mathbf{0 . 8 4 4}$ & $\mathbf{0 . 7 5 3}$ & $\mathbf{0 . 6 9 5}$ \\
\hline
\end{tabular}

Note: See Table A7 for definition of $P S P$. 
Table A9: Robustness check: effect of the treatment on patience, generosity and risk

\begin{tabular}{lccccccc}
\hline $\begin{array}{l}\text { Dependent variable (recall Table 4) } \\
\text { Source }\end{array}$ & Patience & \multicolumn{3}{c}{ Generosity } \\
RCT - survey
\end{tabular}

Notes: ${ }^{*} p<0.1 ;{ }^{* *} p<0.05 ;{ }^{* * *} p<0$. Standard errors are clustered at the group level. Recall Table 4 for definitions of generosity/social preferences, risk preferences, and patience/time preferences. All dependent variables were measured after the intervention and in the same way they were measured before the intervention. Their values pre-intervention are used as controls in the regressions. Additional controls include age, sex, land size, and dummies for the federation, whether the farmer is a leader, and whether the farmer produced crops other than groundnuts, all measured pre-intervention. 
Table A10: Collective commercialization and leader's intentions

\begin{tabular}{|c|c|c|c|c|}
\hline $\begin{array}{l}\text { Dependent variable } \\
\text { Source }\end{array}$ & & $\begin{array}{r}\text { Contribut } \\
\text { RCT - st }\end{array}$ & $\begin{array}{l}\text { d to groul } \\
\text { rvey data }\end{array}$ & \\
\hline B & $\begin{array}{l}73.39 \\
(48.97)\end{array}$ & $\begin{array}{c}108.56 \\
(43.60)^{* *}\end{array}$ & $\begin{array}{l}57.59 \\
(44.72)\end{array}$ & $\begin{array}{c}88.06 \\
(40.47)^{* *}\end{array}$ \\
\hline $\mathrm{C}$ & $\begin{array}{c}133.66 \\
(56.57)^{* *}\end{array}$ & $\begin{array}{c}169.72 \\
(54.83)^{* * *}\end{array}$ & $\begin{array}{c}148.73 \\
(60.85)^{* *}\end{array}$ & $\begin{array}{c}181.64 \\
(58.72)^{* * *}\end{array}$ \\
\hline $\mathrm{D}$ & $\begin{array}{l}125.63 \\
(63.79)^{*}\end{array}$ & $\begin{array}{l}144.68 \\
(59.99)^{* *}\end{array}$ & $\begin{array}{l}70.84 \\
(43.04)\end{array}$ & $\begin{array}{l}117.12 \\
(45.77)^{* *}\end{array}$ \\
\hline Average intentions leader & $\begin{array}{l}0.06 \\
(0.04)\end{array}$ & $\begin{array}{c}0.07 \\
(0.04)^{*}\end{array}$ & & \\
\hline Average intentions simple member & $\begin{array}{r}-0.04 \\
(0.03)\end{array}$ & $\begin{array}{l}-0.06 \\
(0.03)^{*}\end{array}$ & & \\
\hline D X Average intentions leader & $\begin{array}{l}0.06 \\
(0.07)\end{array}$ & $\begin{array}{l}0.03 \\
(0.08)\end{array}$ & & \\
\hline D X Average intentions simple member & $\begin{array}{r}-0.10 \\
(0.07)\end{array}$ & $\begin{array}{l}-0.06 \\
(0.08)\end{array}$ & & \\
\hline Difference intentions leader - simple member $\geq 0$ & & & $\begin{array}{l}46.66 \\
(49.42)\end{array}$ & $\begin{array}{l}49.67 \\
(45.38)\end{array}$ \\
\hline $\mathrm{D} X$ difference $\geq 0$ & & & $\begin{array}{l}43.34 \\
(72.45)\end{array}$ & $\begin{array}{c}6.62 \\
(71.19)\end{array}$ \\
\hline Size of Group & $\begin{array}{c}7.14 \\
(2.03)^{* * *}\end{array}$ & $\begin{array}{c}6.97 \\
(2.18)^{* * *}\end{array}$ & $\begin{array}{c}7.52 \\
(1.96)^{* * *}\end{array}$ & $\begin{array}{c}7.19 \\
(1.92)^{* * *}\end{array}$ \\
\hline Control group mean & & & 58 & \\
\hline $\begin{array}{l}R^{2} \\
N\end{array}$ & $\begin{array}{l}0.15 \\
868\end{array}$ & $\begin{array}{l}0.19 \\
868\end{array}$ & $\begin{array}{l}0.14 \\
868\end{array}$ & $\begin{array}{l}0.18 \\
868\end{array}$ \\
\hline Control & No & Yes & No & Yes \\
\hline
\end{tabular}

Notes: ${ }^{*} p<0.1$; ** $p<0.05 ;{ }^{* *} p<0.01$. Standard errors are clustered at the group level. The dependent variable is the quantity of groundnuts sold through the group. Average intentions are used as an explanatory variable. This information was only revealed in the RCT Group D. Controls include age, sex, land size, generosity, risk aversion measures and time preferences elicited through hypothetical questions (recall Table 4), and dummies for the federation, whether the farmer is a leader, and whether the farmer produced crops other than groundnuts, all measured pre-intervention. A dummy for whether the individual indicated positive intentions to sell through the group is also added. 


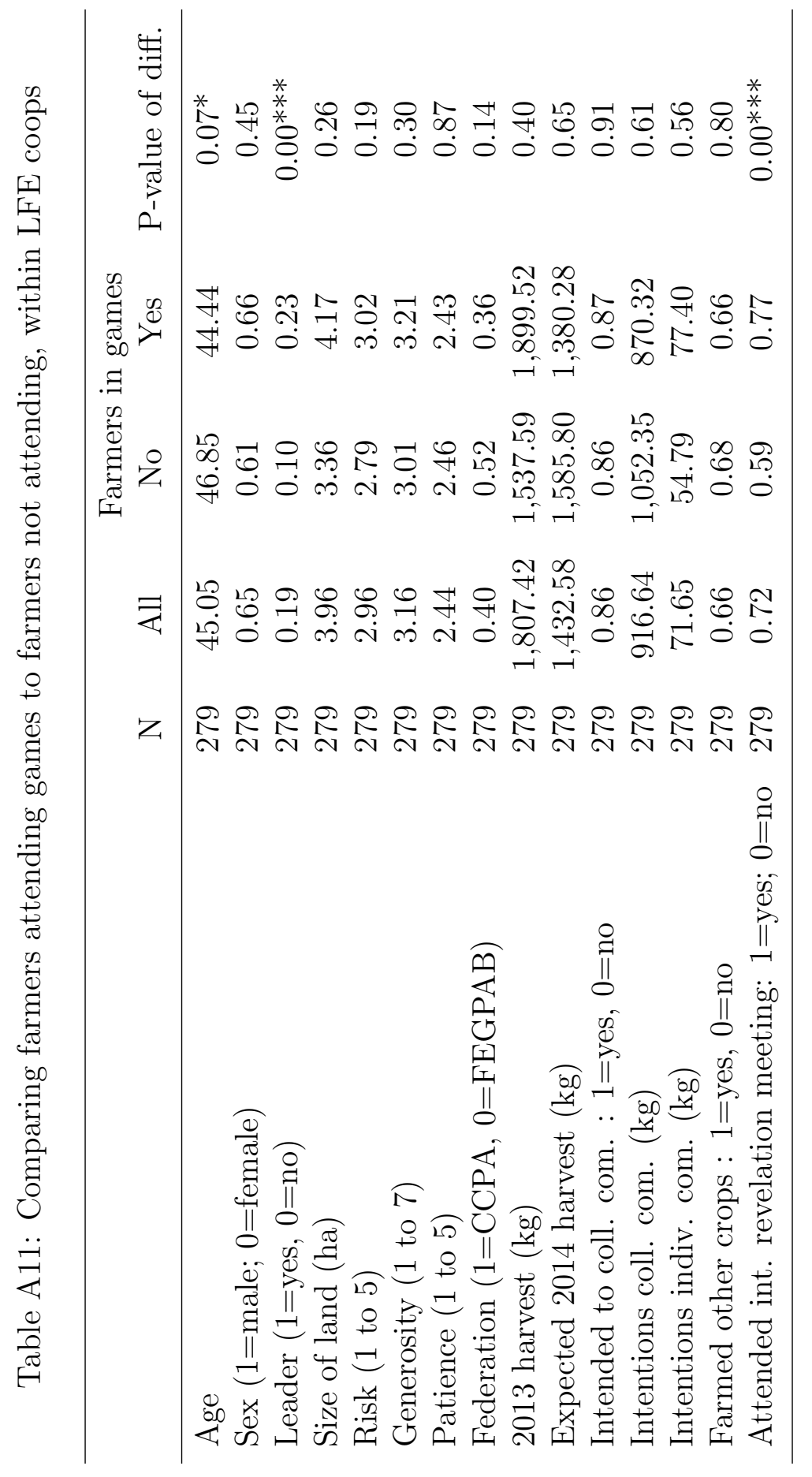

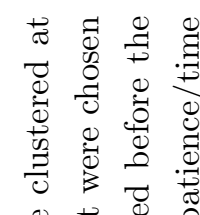

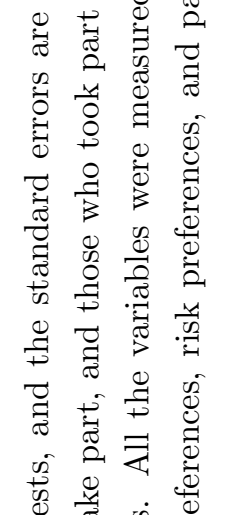
के

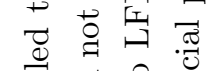

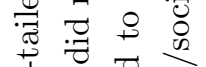

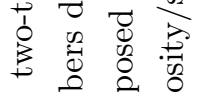

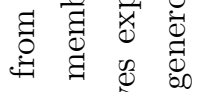
总老.

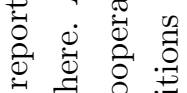

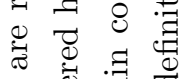

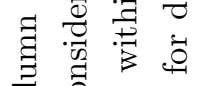

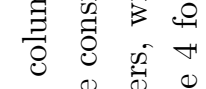

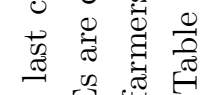
秀空嵌 .

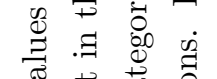
需范

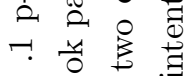



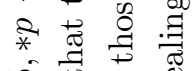

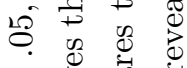
$\checkmark$. * $\begin{array}{lll} & \pi & 0 \\ * & 0 & 0 \\ * & 0 & 0 \\ 0\end{array}$

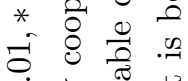

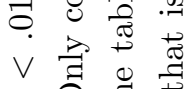
₹

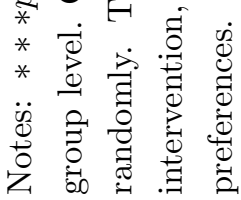

